MEASUREMENT OF THE BULK ACOUSTIC PROPERTIES

\title{
OF FIBROUS MATERIALS AT HIGH TEMPERATURES
}

\author{
Paul Williams \\ School of Engineering and Design, \\ Mechanical Engineering, \\ Brunel University, \\ Uxbridge, Middlesex, UB8 3PH, UK.
}

\author{
Ray Kirby* \\ School of Engineering and Design, \\ Mechanical Engineering, \\ Brunel University, \\ Uxbridge, Middlesex, UB8 3PH, UK. \\ ray.kirby@brunel.ac.uk
}

\author{
Colin Malecki \\ AAF Ltd., \\ Bassington Lane, \\ Cramlington, NE23 8AF \\ Northumberland, UK
}

James Hill

AAF Ltd.,

Bassington Lane,

Cramlington, NE23 8AF

Northumberland, UK

* Corresponding author. 


\begin{abstract}
It is common for fibrous porous materials to be used in high temperature applications such as automotive and gas turbine exhaust silencers. Understanding the effect of temperature on the acoustic properties of these materials is crucial when attempting to predict silencer performance. This requires knowledge of the bulk acoustic properties of the porous materials and so this article aims to quantify the effect of temperature on the bulk acoustic properties of three fibrous materials: rock wool, basalt wool and an E-glass fibre. Measurements are undertaken here using a standard impedance tube that has been modified to accommodate temperatures of up to $500{ }^{\circ} \mathrm{C}$. It is shown that measured data for the bulk acoustic properties may be collapsed using a standard Delany and Bazley curve fitting methodology provided one modifies the properties of the material flow resistivity and air to account for a change in temperature. Moreover, by using a previously proposed power law describing the dependence of the flow resistivity with temperature, one may successfully collapse data measured at every temperature and obtain the Delany and Bazley coefficients in the usual way. Accordingly, to predict the bulk acoustic properties of a fibrous material at elevated temperatures it is necessary only to measure these properties at room temperature, and then to apply the appropriate temperature corrections to the properties of the material flow resistivity and air when using the Delany and Bazley formulae.
\end{abstract}




\section{INTRODUCTION}

The bulk acoustic properties of porous materials play a crucial role in determining how sound propagates within a material. A knowledge of how sound propagates within a material is essential in the study of those applications in which the material is considered to be bulk reacting. Relevant applications include the study of dissipative silencers where it is widely accepted that one must account for the propagation of sound within the material in order to obtain satisfactory estimations of silencer performance. Examples of this approach include automotive exhaust silencers [1-3], and those silencers found in ventilation and gas turbine systems $[4,5]$. In these applications fibrous materials are normally used and here it is common for the material to be sourced in large quantities, a portion of which is then packed into the silencer carcass. This results in many silencer applications containing relatively large quantities of fibrous materials in which the fibres are randomly aligned, and with a significant range in fibre diameters being common. Therefore, for this type of application the identification of the bulk acoustic properties is challenging and one must rely on averaging the acoustic behaviour over a number of material samples in order to deliver a reliable guide to overall material behaviour. This makes it very difficult to realise a theoretically based approach to identifying the bulk acoustic properties, and here it is common for a number of empirical constants to be necessary in order to obtain good agreement between prediction and measurement [6-8]. Furthermore, even a semi-empirical model developed using empirical constants is unlikely to reproduce accurately experimental measurements taken over a wide range of different material bulk densities and excitation frequencies. Therefore, for dissipative silencers packed with fibrous materials it is usual practice to rely on experimental measurements when identifying the bulk acoustic properties [1-5]. 
The bulk acoustic properties of fibrous materials are normally written in the form of the propagation constant and characteristic impedance; these properties may be obtained following measurements of surface impedance taken in an impedance tube. In order to accommodate the random nature of a bulk fibrous material it is common practice to measure many samples of a material - generally covering different bulk densities - and to obtain an overall average behaviour through curve fitting. This can be achieved by plotting these measurements using non-dimensional parameters and this was first demonstrated by Delany and Bazley [9], who aggregated measurements taken for a number of different fibrous materials and showed that data for the real and imaginary parts of the bulk acoustic properties may be collapsed onto graphs using a non-dimensional parameter based on the flow resistivity of the fibrous materials. A power law regression analysis then delivers eight coefficients for the bulk acoustic properties, which are normally referred to as the Delany and Bazley coefficients. The method of Delany and Bazley is widely used and forms the basis for the majority of empirical models that quantify sound propagation within bulk fibrous materials. Furthermore, this approach to specifying the bulk acoustic properties of a porous material is almost exclusively used in theoretical models for dissipative silencers [1-5]. However, the data reported by Delany and Bazley, and the vast majority of the studies that have followed, are limited to the measurement of the bulk acoustic properties at room temperature. This presents a problem when attempting to predict dissipative silencer performance at elevated temperatures, because there is little data available to indicate how higher temperatures will affect the acoustic performance of these materials. This is particularly problematic for high temperature silencer applications, such as automotive and gas turbine exhaust silencers, and here it is noticeable that studies have yet to appear in the literature that attempt to predict silencer performance at higher temperatures. A likely reason 
for this is the absence of comprehensive and reliable data for the bulk acoustic properties of fibrous materials at higher temperatures. Accordingly, this article seeks to address this by reporting impedance tube measurements of the bulk acoustic properties of fibrous materials at elevated temperatures.

Numerous studies are available that report the measurement of the bulk acoustic properties of fibrous materials at room temperature, as well as their use in the design of dissipative silencers [1-5]. It has also long been known that one must correct for errors in the Delany and Bazley coefficients if one is attempting to extrapolate data to low frequencies $[10,11]$. The bulk acoustic properties are normally obtained from surface impedance measurements carried out according to the European Standard EN ISO 10534-2:2001 [12]. This standard specifies details of the impedance tube and the transfer function measurements required to find the surface impedance of the porous sample. The bulk acoustic properties are then found from two separate impedance measurements, which may be achieved by using, for example, two different air gaps behind the sample, or two different thicknesses [13]. It is this post processing of the surface impedance measurements that delivers the bulk acoustic properties of the material, which are very different to surface impedance, or absorption coefficient, often quoted in the literature for porous materials [14]. Following the measurement of the flow resistivity of the porous material [15] one may then obtain the Delany and Bazley coefficients [9]. The influence of temperature on the bulk acoustic properties coefficients has, however, yet to be explored in detail. This is, perhaps, not surprising given the challenge of undertaking impedance tube measurements at high temperatures. However, Sun et al. [14] recently introduced an experimental apparatus in which it was demonstrated that the surface impedance measurements can be obtained reliably at higher temperatures. This approach is also well suited to obtaining experimental measurements of the bulk acoustic properties, and 
so the apparatus described by Sun et al. will form the basis of the experimental investigation that follows.

There are very few studies in the literature that attempt to quantify the influence of elevated temperatures on the acoustic properties of fibrous materials and, to the best of the authors' knowledge, no studies that measure the bulk acoustic properties at high temperatures using an ISO 10534-2 standard test rig [12]. The first study on the effect of high temperatures was carried out by Christie [16], who measured the Delany and Bazley coefficients for mineral wool at $19^{\circ} \mathrm{C}, 255^{\circ} \mathrm{C}$ and $490^{\circ} \mathrm{C}$. Christie used a closed cavity experimental apparatus in order to raise the temperature of the fibrous material, and here it is not entirely clear how accurate this experimental apparatus is likely to be, and it does not, of course, comply with later ISO standards. Christie also measured the flow resistivity of the material over a range of temperatures up to and including $700^{\circ} \mathrm{C}$, and here Christie found an increase in the flow resistivity of the material proportional to the $0.6^{\text {th }}$ power of the (absolute) temperature for temperatures up to about $400^{\circ} \mathrm{C}$. Above this temperature the rate of increase begins to slow down and this power law no longer fits Christie's experimental data. Christie then compared values for the bulk acoustic properties measured at high temperatures with those predicted using Delany and Bazley's coefficients, after first modifying the flow resistivity to account for the higher temperatures. Christie demonstrated reasonably good agreement between the two results and concluded that the power law relationship for the flow resistivity was successful, at least over the temperature range of the acoustic measurements. However, Christie only measured data at two elevated temperatures and reports little data with which to substantiate the final conclusions; agreement between data measured at high temperatures and that predicted using the Delany and Bazley coefficients is also limited at certain frequencies. Therefore, one cannot be certain that the discrepancies evident in Christie's 
results are not caused by a departure of the material properties from those measured by Delany and Bazley, or by experimental error. Here, a question mark also remains over the accuracy of the experimental methodology for the acoustic measurements, especially as the design of the apparatus departs significantly from current practice [12]. Furthermore, Christie does not measure a sufficient amount of data in order to obtain a representative average behaviour for the material. Thus, the measurements provided by Christie are too limited to provide confidence in the method used to extrapolate the data of Delany and Bazley to higher temperatures. Nevertheless, Christie's findings are interesting, especially as there is a clear and obvious advantage to using the power law relationship proposed for the material flow resistivity, as this would permit the Delany and Bazley coefficients measured at room temperature to be used at higher temperatures without actually measuring the acoustic properties at higher temperatures.

The power law profile for flow resistivity proposed by Christie [16] was later investigated by Giese et al. [17], who used a microstructure model to investigate the influence of temperature on the acoustic properties of a fibrous material. Giese et al. predict modifications to the material flow resistivity that are similar to those proposed by Christie, although no experimental data was obtained to support these conclusions. Recently, high temperature measurements were also undertaken by Sun et al. [14], who used an ISO standard impedance tube to obtain measurements of surface impedance up to a temperature of $500^{\circ} \mathrm{C}$. Sun et al. were interested in the surface impedance of a thin disk of steel wool and showed that the absorption coefficient of this material decreased when the temperature increased, at least up to a frequency of about $5 \mathrm{kHz}$. Sun et al. [14] also demonstrated good agreement between measured and predicted absorption coefficient using a microstructure based theory. This approach allowed Sun et al. to investigate the influence of temperature on those parameters 
typically used in theoretical models for porous media. However, Sun et al. did not proceed to measure the bulk acoustic properties of the porous material and here it is likely to be difficult to extend their theoretical approach to the investigation of the propagation constant and characteristic impedance. This is because it is likely to be more challenging to obtain good agreement between prediction and measurement for the propagation of sound within random bulk samples of a fibrous material, when compared to the surface impedance of a thin rigid disk of material.

The experimental method of Sun et al. demonstrates that it is possible to build an impedance tube based on an ISO standard design and to modify the tube to allow measurements to be obtained at higher temperatures. Accordingly, their experimental methodology is adopted here as a basis for undertaking the measurement of the bulk acoustic properties of fibrous materials used in dissipative silencers. The aim of these measurements is to investigate the validity of the temperature power law proposed by Christie for the material flow resistivity [16], and its use in quantifying the bulk acoustic properties of fibrous materials at high temperatures using Delany and Bazley coefficients. Accordingly, three fibrous materials typically used in high temperature applications are measured here. These materials are rock wool, basalt wool and a glass fibre, where the maximum operating temperature for these materials is $800^{\circ} \mathrm{C}, 820^{\circ} \mathrm{C}$ and $500^{\circ} \mathrm{C}$, respectively. In section 2 , an impedance tube designed according to EN ISO 10534-2:2001 [12] is described, with modifications made to allow the temperature to be raised up to $500^{\circ} \mathrm{C}$. In section 3 , measured data is presented in the form of the propagation constant and characteristic impedance for each material, and here the validity of Christie's modification to flow resistivity is investigated. 


\section{EXPERIMENT}

The experiments undertaken here are based on the impedance tube methodology described in EN ISO 10534-2:2001 [12], as well as the high temperature modifications to the tube suggested by Sun et al. [14]. Accordingly, a steel impedance tube of inner diameter $102 \mathrm{~mm}$ and length $1510 \mathrm{~mm}$ is used, see Fig. 1. This gives a nominal upper frequency limit of 1951 $\mathrm{Hz}$ at room temperature, and $3120 \mathrm{~Hz}$ at $500^{\circ} \mathrm{C}$. Two GRAS type 40SA probe microphones are used to measure sound pressure and these are placed $79 \mathrm{~mm}$ apart, with the first microphone placed $201 \mathrm{~mm}$ from the sample face. The upper operating temperature of the microphones is $70^{\circ} \mathrm{C}$ and so they are isolated from the high temperatures in the tube using a $160 \mathrm{~mm}$ long probe and a heat sink that has an upper operating limit of $800^{\circ} \mathrm{C}$. The tube is terminated with a plunger of depth $30 \mathrm{~mm}$, which may be moved away from the back of the sample material using a screw thread attached to a plunger. When the plunger is moved to create an air gap the sample is held in position using a metallic wire mesh of high percentage open area, with the mesh being slightly oversized to keep it in place. The maximum available air gap is $225 \mathrm{~mm}$, although the actual air gap chosen is varied according to the size and bulk density of the sample material. The sound source is a Maplin Electronics Ltd 51/4" 60W Shielded Loudspeaker, which is placed at the far end of the impedance tube.

Heating is provided by 11 Watlow Mineral Insulated Band Heaters, which have a width of $63.5 \mathrm{~mm}$ and are spaced equally over the tube so that they cover approximately $700 \mathrm{~mm}$ of the tube starting at the back plate of the tube, see Fig 2. The maximum rated temperature of each heater is $540^{\circ} \mathrm{C}$, although in the experiments that follow the upper temperature is restricted to $500^{\circ} \mathrm{C}$ due to electrical safety reasons. The temperature of each heater is 
controlled by a set of three controllers so that individual heaters are grouped into three sections, with 1 heater in the first group next to the back plate termination, 8 heaters in the next group and 2 heaters in the final group furthest away from the sample. In order to prevent thermal damage to the loudspeaker a water jacket with a length of $614 \mathrm{~mm}$ is used to cool the air in the section of the tube closest to the loudspeaker.

The main challenge of operating the impedance tube at high temperatures is maintaining a constant temperature along the length of the tube, including the material sample and the plunger. The temperature of the heaters is set by the controllers and these have an inbuilt feedback mechanism in order to maintain a specified temperature. This feedback depends on temperature measurements obtained for each group of heaters and here three type $\mathrm{K}$ thermocouples were fixed inside the tube, one for each group of heaters. In addition, the temperature profile inside the tube was also independently investigated using a separate array of five Type K thermocouples. These measurements were obtained prior to the acoustic tests, which enabled the loudspeaker to be removed from the far end of the tube and replaced with a steel plate. Each thermocouple was then threaded inside a narrow metal tube, which was inserted through the steel plate and moved along the tube into one of 12 axial measurement positions. At a chosen axial location the thermocouples were arranged so that they were approximately $10 \mathrm{~mm}, 30 \mathrm{~mm}, 50 \mathrm{~mm}, 70 \mathrm{~mm}$ and $90 \mathrm{~mm}$ away from the bottom of the impedance tube, in order to measure the transverse temperature distribution at five points. The thermocouples permitted the independent measurement of the performance of each heater and following the setting of a desired temperature on the controller some oscillation around this temperature took place and it took about 60 minutes for the temperature readings to settle down. Initial temperature measurements inside the tube showed up large convection currents and significant heat losses at the water jacket end, and it was found necessary to 
place a thin cloth barrier between the heater and water jacket sections of the tube in order to lower axial temperature gradients. A number of experimental measurements were undertaken to ascertain the effect of this cloth barrier on the acoustic measurements and, provided one chooses a relatively thin barrier, this material had a negligible influence on the acoustic measurements. Following this design modification a significant improvement in the temperature profile was realised, and in Figs 3a-3c this temperature distribution is shown at temperatures of $300^{\circ} \mathrm{C}, 400^{\circ} \mathrm{C}$ and $500^{\circ} \mathrm{C}$, respectively. It is evident in these figures that a relatively constant temperature distribution has been achieved inside the tube, at least between the face of the plunger and the last microphone. This region of the tube near the plunger formed the main focus of efforts to maintain a uniform temperature profile in the anticipation that any increase in the temperature gradients beyond the last microphone will not significantly affect the acoustic measurements. For this region the maximum axial temperature difference is $\Delta T_{x}^{\max }=3.4^{\circ} \mathrm{C}$ at $300^{\circ} \mathrm{C}$, which occurs for a single radial location; for all other radial locations and at other temperatures the maximum axial temperature difference is closer to $2{ }^{\circ} \mathrm{C}$, and here the average of these values is $\Delta \bar{T}_{x}^{\max }=2.0^{\circ} \mathrm{C}$. In the radial direction agreement between the measured temperatures improves, with $\Delta T_{r}^{\max }=2{ }^{\circ} \mathrm{C}$ at $300{ }^{\circ} \mathrm{C}$, with most values closer to $1{ }^{\circ} \mathrm{C}$, so that $\Delta \bar{T}_{r}^{\max }=0.9^{\circ} \mathrm{C}$. For the entire set of data measurements at each temperature, the standard deviation from the mean is $\mathrm{SD}=0.9{ }^{\circ} \mathrm{C}$ at $300{ }^{\circ} \mathrm{C}, \mathrm{SD}=0.8{ }^{\circ} \mathrm{C}$ at $400{ }^{\circ} \mathrm{C}$, and $\mathrm{SD}=0.6{ }^{\circ} \mathrm{C}$ at $500{ }^{\circ} \mathrm{C}$. Thus, the measured temperature distribution within the tube indicates that the temperature profile remains stable and errors seen in the axial and transverse temperature profiles compare very well with the values obtained by Sun et al. [14]. Accordingly, it is assumed here that this variation in temperature is acceptable for undertaking acoustic measurements because the average variation in the speed of sound will be less than $1 \%$, which means that the sound pressure distribution within the tube will remain planar. 
The experimental measurement of surface impedance follows the transfer function method described in EN ISO 10534-2:2001 [12], with appropriate changes made to the fluid constants when measuring at higher temperatures. In the measurements undertaken here a single sample of fibrous material is maintained in place whilst testing is undertaken at all temperatures of interest. Before testing at a given temperature, the temperature of the tube was allowed to stabilise. Two surface impedance tests were then performed, one with a rigid backing the other with an air gap behind the material. In each case, the temperature in the tube was allowed to stabilise following the introduction of an air gap. The size chosen for the air gap depended on the material measured, although it generally varied between 25 and 90 $\mathrm{mm}$. Following the completion of two surface impedance tests at each temperature the bulk acoustic properties are determined using the method described by Utsuno et al. [13], which is amended here to accommodate the use of a rigid backing. The material sample was then replaced with a sample of the same material but with a different bulk density and a number of repetitive tests were undertaken, where the bulk density of the sample was varied between 60 and $130 \mathrm{~kg} / \mathrm{m}^{3}$ and a sample thickness of less than $40 \mathrm{~mm}$ was maintained in order to avoid high levels of attenuation within the sample material that may significantly lower the signal to noise ratio. The testing of random samples of bulk fibrous materials does, however, present some problems, especially when attempting to maintain a relatively uniform distribution of the material across the sample. Accordingly, it is important to include a sufficient amount of material to allow one to minimise large voids inside the material and also to evenly distribute the material, but not too much so that high levels of attenuation compromise the accuracy of the measurements. This approach required a significant amount of trial and error when arranging the material sample and it was found that occasionally the material settles in such a way that clearly erroneous data is obtained. Therefore, those sets of 
data that significantly depart from the average expected behaviour have been discarded from the results that follow.

\section{RESULTS AND DISCUSSION}

The measured bulk acoustic properties for rock wool, basalt wool and glass fibre are presented here using the method of Delany and Bazley [9]. Accordingly, the bulk acoustic properties written as

$$
\Gamma=\alpha+i \beta, \quad \text { and } \quad z=R+i X
$$

where $\Gamma$ is the propagation constant and $z$ is the characteristic impedance, with $i=\sqrt{-1}$. The bulk acoustic properties are then written in terms of the Delany and Bazley coefficients so that

$$
\frac{\Gamma}{k}=a_{1} \xi^{a_{2}}+i\left[1+a_{3} \xi^{a_{4}}\right]
$$

and

$$
\frac{z}{\rho c}=1+a_{5} \xi^{a_{6}}-i a_{7} \xi^{a_{8}}
$$

where $a_{1} \ldots . a_{8}$ are the Delany and Bazley coefficients and $\xi=\rho f / \sigma$. Here, $k=\omega / c$, where $\omega$ is the radian frequency, $c$ is the speed of sound, $\rho$ is the density of air, $\sigma$ is the flow resistivity of the material and $f$ denotes frequency. Note that $\sigma$ is assumed here to be a 
function of temperature [16], and of course $\rho$ and $c$ also depend on temperature. Thus, in order to obtain the Delany and Bazley coefficients at higher temperatures one must also measure the temperature dependence of $\sigma$. It is, however, sensible first to investigate the power law suggested by Christie [16] for the flow resistivity before deciding whether it is necessary to incur the extra expense of commissioning a high temperature flow resistivity rig. Accordingly, the flow resistivity for each material is measured here at room temperature following EN ISO 29053:1993 [15]. The values obtained are expressed in the form [11], $\sigma_{0}=b_{1} \rho_{m}^{b_{2}}$, where $\rho_{m}$ is the bulk density of the fibrous material and $\sigma_{0}$ is the flow resistivity at room temperature. The coefficients $b_{1}$ and $b_{2}$ are obtained following measurements taken with a number of different bulk densities and these are given in table 1. To extrapolate the flow resistivity to a higher temperature $T$, Christie [16] proposes the following power law relationship

$$
\sigma=\sigma_{0}\left(\frac{T}{T_{0}}\right)^{0.6}
$$

where $T_{0}$ is a room temperature of $20^{\circ} \mathrm{C}$, and all temperatures in Eq. (4) are in degrees Kelvin.

The bulk acoustic properties measured for rock wool are shown in Figs. 4a-d. Here, data was obtained at $20^{\circ} \mathrm{C}, 200^{\circ} \mathrm{C}, 300^{\circ} \mathrm{C}, 400^{\circ} \mathrm{C}$ and $500^{\circ} \mathrm{C}$. It is evident in Figs. $4 \mathrm{~b}$ and $4 \mathrm{c}$ that a certain amount of scatter is present, especially in the values for $\beta$ and $R$. This is common in measurements of the bulk acoustic properties taken at room temperature; see for example the levels of scatter observed for these parameters by a number of authors [18-20]. Thus, the scatter seen here is not necessarily caused by the increase in temperature, which is illustrated 
by a comparison between data taken at room temperature and those at elevated temperatures. Accordingly, it is concluded here that high temperatures do not affect the level of scatter seen in the data and this scatter is merely a function of the measurement methodology. The scatter has many possible sources and may be influenced by the accuracy of the transfer function measurements, with lower frequencies being less accurate because of the increase in the wavelength of sound; however, for fibrous materials it is likely that the scatter is dominated by problems in obtaining a uniform sample of the material, as well as maintaining a flat and uniform surface facing towards the sound source. Nevertheless, the scatter seen in the results for rock wool is judged to be acceptable for the deduction of the bulk acoustic properties.

In Fig. 4, it is evident that if one adopts the power law in Eq. (4) then the data measured at different temperatures collapses well. For example, when the temperature is increased the data for $\alpha, R$ and $X$ are seen to "line up" very well. The only region of slight deviation is for $\beta$, however this is for one of the material properties that has the most scatter, and the level of deviation seen here is not deemed to be significant in terms of the effect of temperature on the acoustic properties of the material. In Figs. 5 and 6, the bulk acoustic properties for basalt wool and glass fibre are presented. Here, the data is again seen to line up well, and it is noticeable that the scatter for basalt wool is less than that seen for the other materials. This is thought to be caused by the relative ease with which it was possible to arrange this material in a uniform and consistent way. In Fig. 5 one can see that for $\beta$ and $R$ the data at different temperatures lines up well and so one may infer that those small discrepancies seen previously for rock wool are probably a result of experimental uncertainties and not a temperature related property of the material. For glass fibre in Fig. 6 similar behaviour is observed to the other two materials, although there is an increase in scatter when compared to basalt wool. 
It is evident in Figs. 4-6 that the measured bulk acoustic properties obtained at high temperatures generally collapse very well onto a standard Delany and Bazley plot. This was made possible by compensating for the change in the flow resistivity of the material and the properties of air when the temperature is increased. Accordingly, these figures provide convincing evidence that the power law modification of Eq. (4), first suggested by Christie [16], is correct, at least up to a temperature of $500^{\circ} \mathrm{C}$. Therefore, it is possible to fit a regression curve through this data and to identify the Delany and Bazley coefficients for each material, and these are recorded here in Table 1. It is likely that any differences Christie noticed between predicted values obtained with the corrected flow resistivity, and those values measured at high temperatures, were caused by comparing a limited set of data for an individual material with data averaged over many measurements and different materials taken by Delany and Bazley. This effect is also evident in the regression constants in Table 1, which do not match those of Delany and Bazley, and do not match one another. Christie also noted a deviation in Eq. (4) when measuring the flow resistivity at temperatures above $400^{\circ} \mathrm{C}$, but in Figs. 4-6 there is no evidence to suggest that this occurs for the materials studied here. For example, those measurements taken at $500^{\circ} \mathrm{C}$ appear to collapse just as well as those taken at lower temperatures and there is no evidence of any trend in the data deviating away from that obtained at lower temperatures. Whilst it has not been possible to obtain data at temperatures above $500^{\circ} \mathrm{C}$, the data presented here provides evidence that one may, at least as a first approximation, apply the power law relationship of Eq. (4) over the entire temperature range of interest, which for gas turbine exhaust systems is up to $680^{\circ} \mathrm{C}$. 
In Delany and Bazley's original article the absorption coefficient $\alpha_{n}$ was also obtained, which may readily be obtained from the bulk acoustic properties, so that

$$
\alpha_{n}=1-\left|\frac{z_{\mathrm{w}}-1}{z_{\mathrm{w}}+1}\right|^{2}
$$

where $z_{w}=z \operatorname{coth}(\Gamma d) / \rho c$. Here, Eq. (5) permits a measured value for the absorption coefficient to be calculated for a given depth of material using the bulk acoustic property measurements. This permits comparison with the findings of Sun et al. [14] and in Fig. 7 the effect of temperature on the absorption coefficient of rock wool is shown for a material depth of $d=16 \mathrm{~mm}$, with $\sigma_{0}=8.5 \times 10^{4} \mathrm{Ns} / \mathrm{m}^{4}$. Here, it is seen that the measured absorption coefficient drops as the temperature is increased, at least over the frequency range covered here and this behaviour is the same as that observed by Sun et al. [14]. The material studied by Sun et al. is, however, very different from those studied here and so only a qualitative comparison is possible, but the results do clearly demonstrate that a rise in temperature significantly alters the absorption characteristics of a fibrous porous material.

\section{CONCLUSIONS}

The influence of temperature on the bulk acoustic properties of three fibrous materials was investigated using an impedance tube designed to ISO 10534-2 standards [12] and adapted for high temperatures following the methodology of Sun et al. [14]. It is shown that by using band heaters it is possible to maintain an approximately linear temperature profile throughout the tube for temperatures up to $500{ }^{\circ} \mathrm{C}$. Through the use of probe microphones and a water cooling jacket close to the loudspeaker, one may then use a two microphone method to 
measure the surface impedance of a sample of fibrous material at high temperatures. The bulk acoustic properties may then be found following the measurement of two different surface impedances [13]. Measured data are presented here for rock wool, basalt wool and an E-glass fibre, for temperatures between $20{ }^{\circ} \mathrm{C}$ and $500{ }^{\circ} \mathrm{C}$. For each material it is shown that one may collapse the data using the method of Delany and Bazley [9]; however, in order for this to work it is necessary first to correct for the temperature dependence of the material flow resistivity, as well as that of the properties of air. Here, it is shown that the 0.6 power law relationship between temperature and the material flow resistivity proposed by Christie [16] permits the data measured at each temperature to be collapsed onto standard Delany and Bazley curves, at least up to a temperature of $500{ }^{\circ} \mathrm{C}$. That is, if one wishes to obtain the bulk acoustic properties of a fibrous material at high temperatures then it is necessary only to measure these properties at room temperature, and then to correct the flow resistivity using Christie's power law given in Eq. (4), as well as modify the properties of air. Therefore the measurements presented here demonstrate that it is not necessary to build an impedance tube that will operate at high temperatures, at least if one is interested in the properties of fibrous materials up to $500{ }^{\circ} \mathrm{C}$. For temperatures above $500{ }^{\circ} \mathrm{C}$ it is proposed that, as a first approximation, one retains the 0.6 power law, provided that the material remains mechanically stable at such high temperatures. The results presented here also demonstrate that high temperatures significantly affect the acoustic properties of a fibrous material and so any computational models that seek to estimate dissipative silencer performance at higher temperatures must account for this in their calculations. 


\section{ACKOWLEDGEMENTS}

The authors would like to thank the UK Technology Strategy Board (TSB), through the Knowledge Transfer Programme (KTP), for their support of the work reported in this article. 
1. Kirby R, Denia FD. Analytic mode matching for a circular dissipative silencer containing mean flow and a perforated pipe, Journal of the Acoustical Society of America 2007;122:3471-3482.

2. Selamet A, Xu MB, Lee IJ, Huff NT. Analytical approach for sound attenuation in perforated dissipative silencer, Journal of the Acoustical Society of America 2004;115:2091-2099.

3. Kirby R. A comparison between analytic and numerical methods for modelling automotive dissipative silencers with mean flow, Journal of Sound and Vibration 2009;325:565-582.

4. Cummings A, Sormaz N. Acoustic attenuation in dissipative splitter silencers containing mean fluid flow, Journal of Sound and Vibration 1993;168:209-227.

5. Kirby R, Lawrie JB. A point collocation approach to modelling large dissipative silencers, Journal of Sound and Vibration 2005;286:313-339.

6. Johnson DL, Køplik J, Dashen R. Theory of dynamic permeability and tortuosity in fluidsaturated porous media, Journal of Fluid Mechanics 1987;176:379-402.

7. Allard JF. Propagation of sound in porous media, modelling sound absorbing materials. New York. Elsevier Applied Science; 1993.

8. Bo Z, Tianning C. Calculation of sound absorption characteristics of porous sintered fiber metal. Applied Acoustics 2009;70:337-346.

9. Delany ME, Bazley EN. Acoustical properties of fibrous materials. Applied Acoustics 1970;3:105-116.

10. Mechel FP. Ausweitung der absorberformel von Delany and Bazley zu tiefen frequenzen, Acustica 1976;35:210-213. 
11. Kirby R, Cummings A. Prediction of the bulk acoustic properties of fibrous materials at low frequencies, Applied Acoustics 1999;56:101-125.

12. European Standard EN ISO 10534-2:2001, Determination of sound absorption coefficient and impedance in impedance tubes. Transfer function method.

13. H. Utsuno, T. Tanaka, T. Fujikawa, A.F. Seybert, Transfer function method for measuring characteristic impedance and propagation constant of porous materials, Journal of the Acoustical Society of America 1989;86:637—643.

14. F. Sun, H. Chen, J. Wu, K. Feng, Sound absorbing characteristics of fibrous metal materials at high temperatures, Applied Acoustics 2010;71:221-235.

15. European Standard EN ISO 29053:1993, Acoustics: Materials for acoustical applications. Determination of airflow resistance.

16. Christie DRA. Measurement of the acoustic properties of a sound absorbing material at high temperatures, Journal of Sound and Vibration 1976;46:347-355.

17. F. Giese, H.-C. Ries, C. Eigenbrod, On the performance of porous sound absorbent material in high temperature applications, Journal of Engineering for Gas Turbines and Power 2010;132: 121301-1--121301-6.

18. T. Komatsu, Improvement of the Delany-Bazley and Miki models for fibrous soundabsorbing materials, Acoustical Science and Technology 2008;29:121-129.

19. P. Dunn, W.A. Davern, Calculation of Acoustic Impedance of Multi-layer Absorbers, Applied Acoustics 1986;19:321-334.

20. A. Cummings and S.P. Beadle, Acoustic properties of reticulated plastic foams, Journal of Sound and Vibration 1993;175:115-133. 


\section{FIGURE CAPTIONS}

Figure 1. Experimental apparatus (all dimensions in $\mathrm{mm}$ ).

Figure 2. Photograph of experimental apparatus.

Figure 3(a). Measured temperature inside tube at set temperature of $300^{\circ} \mathrm{C}$ and a distance $y$ from the bottom of the tube. $\longrightarrow, y=10 \mathrm{~mm} ;---, y=30 \mathrm{~mm}$; ……......, $y=50 \mathrm{~mm} ;-\cdots-\cdot, y=70 \mathrm{~mm} ;-\cdots-\cdot y=90 \mathrm{~mm}$.

Figure 3(b). Measured temperature inside tube at set temperature of $400^{\circ} \mathrm{C}$ and a distance $y$ from the bottom of the tube. $\longrightarrow, y=10 \mathrm{~mm} ;---, y=30 \mathrm{~mm}$; ……......., $y=50 \mathrm{~mm} ;-\cdots-\cdots, y=70 \mathrm{~mm} ;-\cdots-\cdot, y=90 \mathrm{~mm}$.

Figure 3(c). Measured temperature inside tube at set temperature of $500^{\circ} \mathrm{C}$ and a distance $y$ from the bottom of the tube. $\longrightarrow, y=10 \mathrm{~mm} ;---, y=30 \mathrm{~mm}$;

…..........,$y=50 \mathrm{~mm} ;-\cdot-\cdot \cdot, y=70 \mathrm{~mm} ;-\cdots-\cdot, y=90 \mathrm{~mm}$.

Figure 4a. Real part of the propagation constant for rock wool. $\quad+\quad, 20^{\circ} \mathrm{C}$;

$+\quad, 200^{\circ} \mathrm{C} ; \quad+\quad, 300^{\circ} \mathrm{C} ; \quad+\quad 400^{\circ} \mathrm{C} ; \quad+\quad 500^{\circ} \mathrm{C}$. 
Figure 4(b). Imaginary part of the propagation constant for rock wool. $\quad+\quad, 20^{\circ} \mathrm{C}$;

,$+ 200^{\circ} \mathrm{C} ; \quad+\quad, 300^{\circ} \mathrm{C} ; \quad+400^{\circ} \mathrm{C} ; \quad+500^{\circ} \mathrm{C}$.

Figure 4(c). Real part of the characteristic impedance for rock wool. $\quad+\quad, 20^{\circ} \mathrm{C}$;

,$+ 200^{\circ} \mathrm{C} ; \quad+\quad, 300^{\circ} \mathrm{C} ; \quad+400^{\circ} \mathrm{C} ; \quad+500^{\circ} \mathrm{C}$.

Figure 4(d). Imaginary part of the characteristic impedance for rock wool. $\quad+\quad, 20^{\circ} \mathrm{C}$;

$+\quad, 200^{\circ} \mathrm{C} ; \quad+\quad, 300^{\circ} \mathrm{C} ; \quad+400^{\circ} \mathrm{C} ; \quad+500^{\circ} \mathrm{C}$.

Figure 5(b). Imaginary part of the propagation constant for basalt wool. $\quad+\quad, 20^{\circ} \mathrm{C}$;

,$+ 200^{\circ} \mathrm{C} ; \quad+, 300^{\circ} \mathrm{C} ;+400^{\circ} \mathrm{C} ; \quad+500^{\circ} \mathrm{C}$.

Figure 5(c). Real part of the characteristic impedance for basalt wool. $\quad+\quad, 20^{\circ} \mathrm{C}$;

$+\quad, 200^{\circ} \mathrm{C} ; \quad+, 300^{\circ} \mathrm{C} ;+400^{\circ} \mathrm{C} ;+500^{\circ} \mathrm{C}$.

Figure 5(d). Imaginary part of the characteristic impedance for basalt wool. $\quad+\quad, 20^{\circ} \mathrm{C}$;

$+\quad, 200^{\circ} \mathrm{C} ; \quad+\quad, 300^{\circ} \mathrm{C} ; \quad+400^{\circ} \mathrm{C} ; \quad+500^{\circ} \mathrm{C}$.

Figure 6(a). Real part of the propagation constant for glass fibre. $\quad+\quad, 20^{\circ} \mathrm{C}$;

$+\quad, 200^{\circ} \mathrm{C} ; \quad+\quad, 300^{\circ} \mathrm{C} ; \quad+400^{\circ} \mathrm{C} ; \quad+500^{\circ} \mathrm{C}$. 
Figure 6(b). Imaginary part of the propagation constant for rock wool. $\quad+\quad, 20^{\circ} \mathrm{C}$;

$+\quad, 200^{\circ} \mathrm{C} ; \quad+\quad, 300^{\circ} \mathrm{C} ; \quad+400^{\circ} \mathrm{C} ; \quad+500^{\circ} \mathrm{C}$.

Figure 6(c). Real part of the characteristic impedance for glass fibre. $\quad+\quad, 20^{\circ} \mathrm{C}$;

$+\quad, 200^{\circ} \mathrm{C} ; \quad+\quad, 300^{\circ} \mathrm{C} ; \quad+400^{\circ} \mathrm{C} ; \quad+500^{\circ} \mathrm{C}$.

Figure 6(d). Imaginary part of the characteristic impedance for glass fibre. $\quad+\quad, 20^{\circ} \mathrm{C}$;

$+\quad, 200^{\circ} \mathrm{C} ; \quad+\quad, 300^{\circ} \mathrm{C} ; \quad+400^{\circ} \mathrm{C} ; \quad+500^{\circ} \mathrm{C}$.

Figure 7. The absorption coefficient of basalt wool calculated from the derived Delany and Bazley coefficients.,$- 20^{\circ} \mathrm{C} ;---, 200^{\circ} \mathrm{C} ; \cdots \cdots \cdots \cdots \cdots \cdots \cdot, 300^{\circ} \mathrm{C}$;

$-\cdot-\cdot, 400^{\circ} \mathrm{C} ;-\cdots-\cdot, 500^{\circ} \mathrm{C}$. 


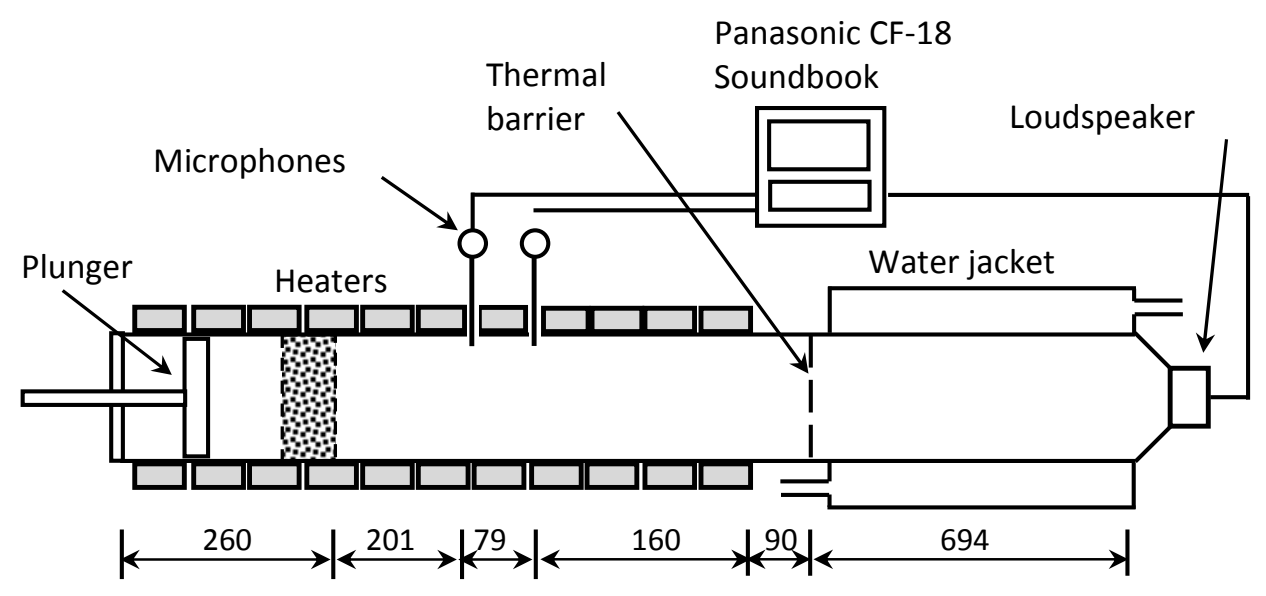

Figure 1. Experimental apparatus (all dimensions in $\mathrm{mm}$ ). 


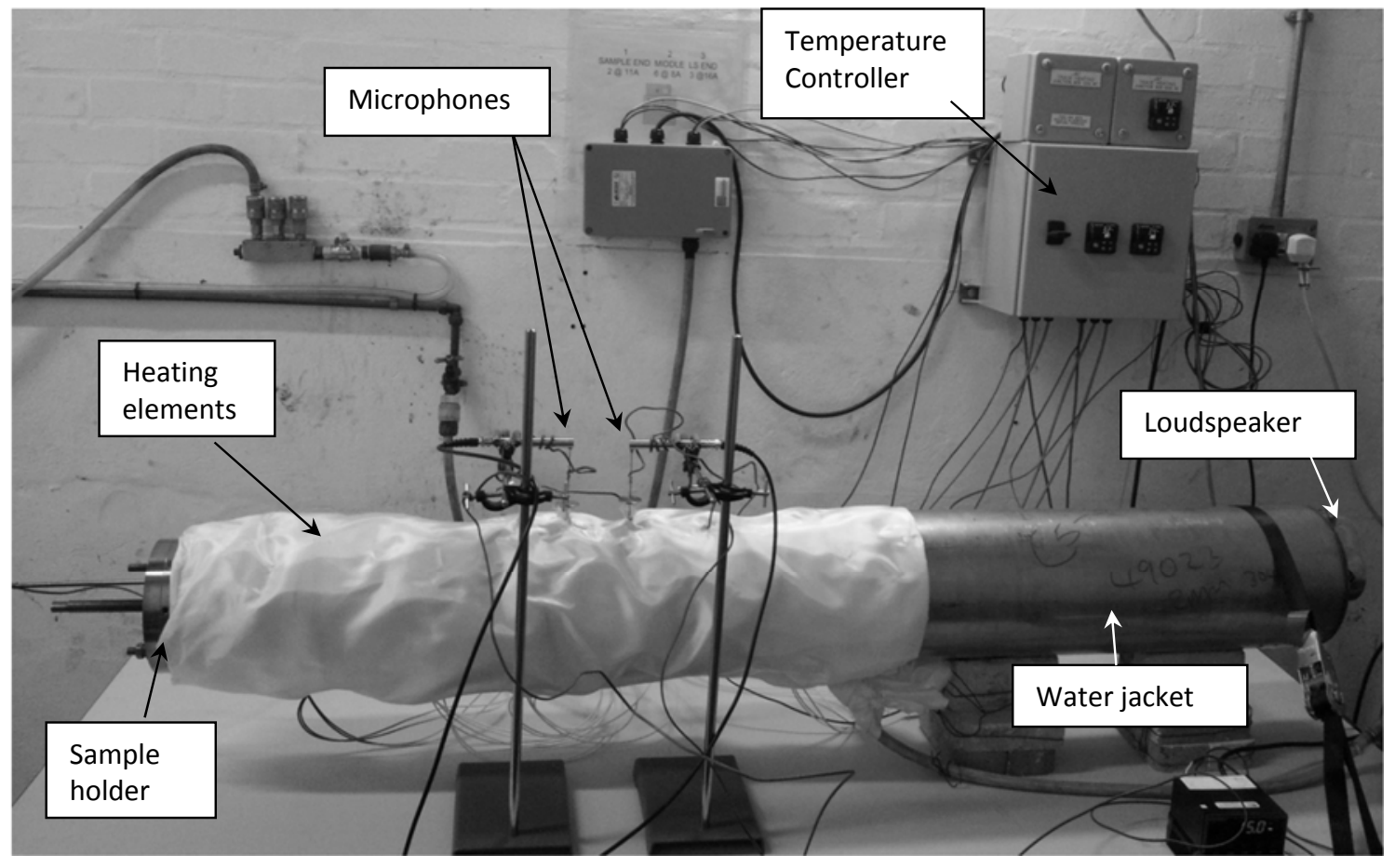

Figure 2. Photograph of experimental apparatus. 


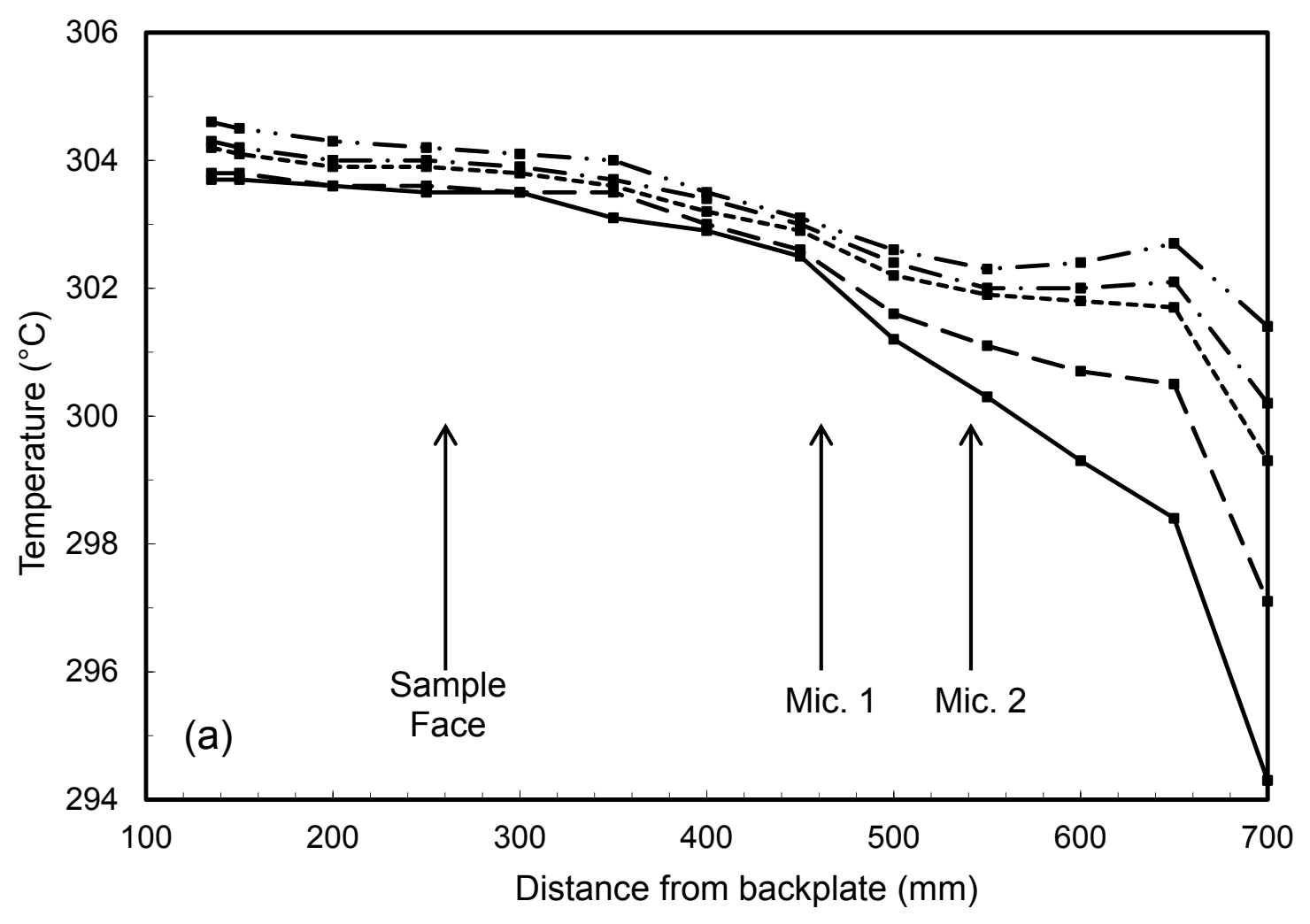

Figure 3(a). Measured temperature inside tube at set temperature of $300^{\circ} \mathrm{C}$ and a distance $y$ from the bottom of the tube. $\longrightarrow, y=10 \mathrm{~mm}$; $-ー, y=30 \mathrm{~mm}$;

,$y=50 \mathrm{~mm} ;-\cdots \cdot \cdot, y=70 \mathrm{~mm} ;-\cdots-\cdot, y=90 \mathrm{~mm}$. 


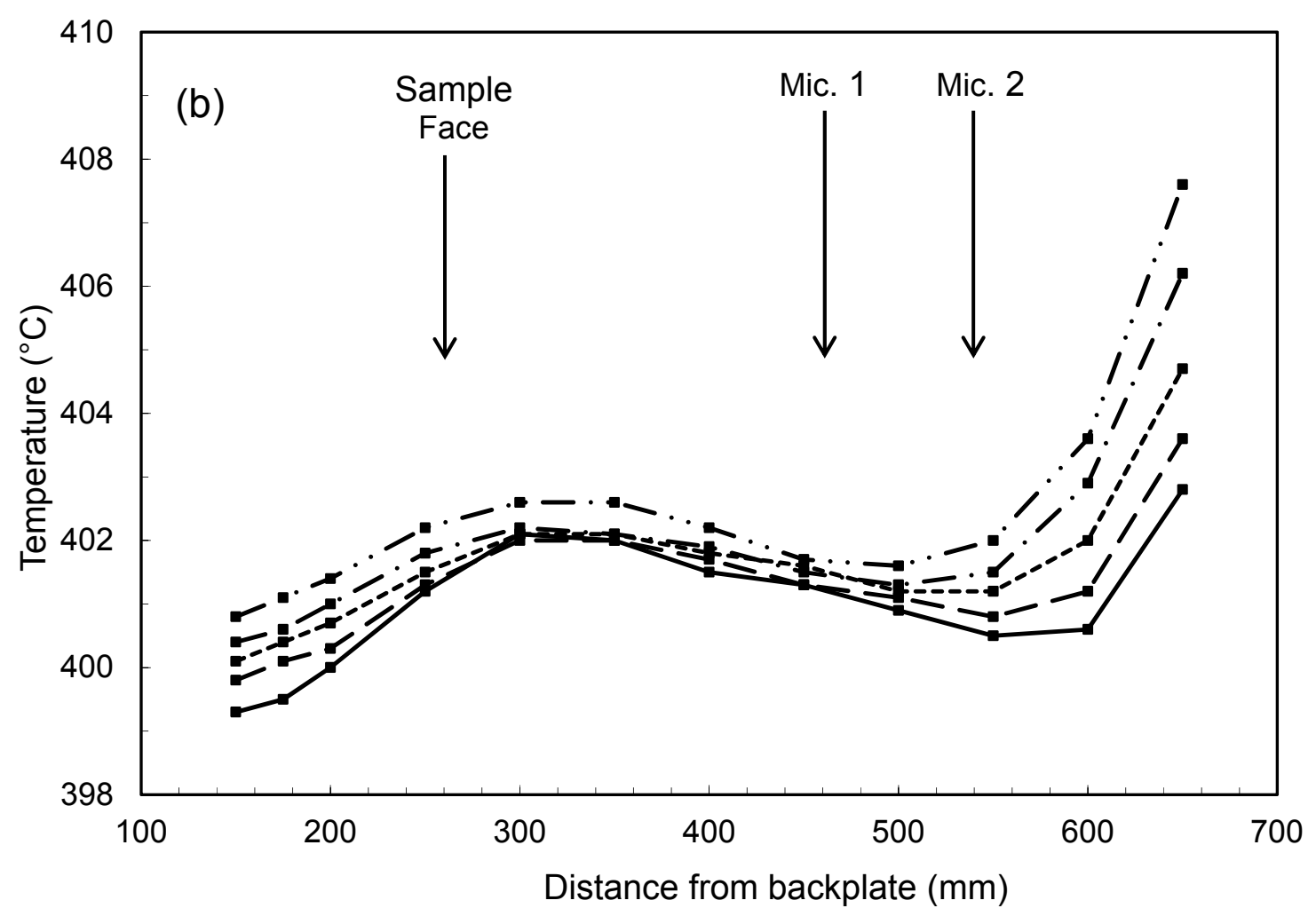

Figure 3(b). Measured temperature inside tube at set temperature of $400^{\circ} \mathrm{C}$ and a distance $y$ from the bottom of the tube. $\longrightarrow, y=10 \mathrm{~mm}$; - -,$y=30 \mathrm{~mm}$; ,$y=50 \mathrm{~mm} ;-\cdots-\cdot, y=70 \mathrm{~mm} ;-\cdots-\cdot, y=90 \mathrm{~mm}$ 


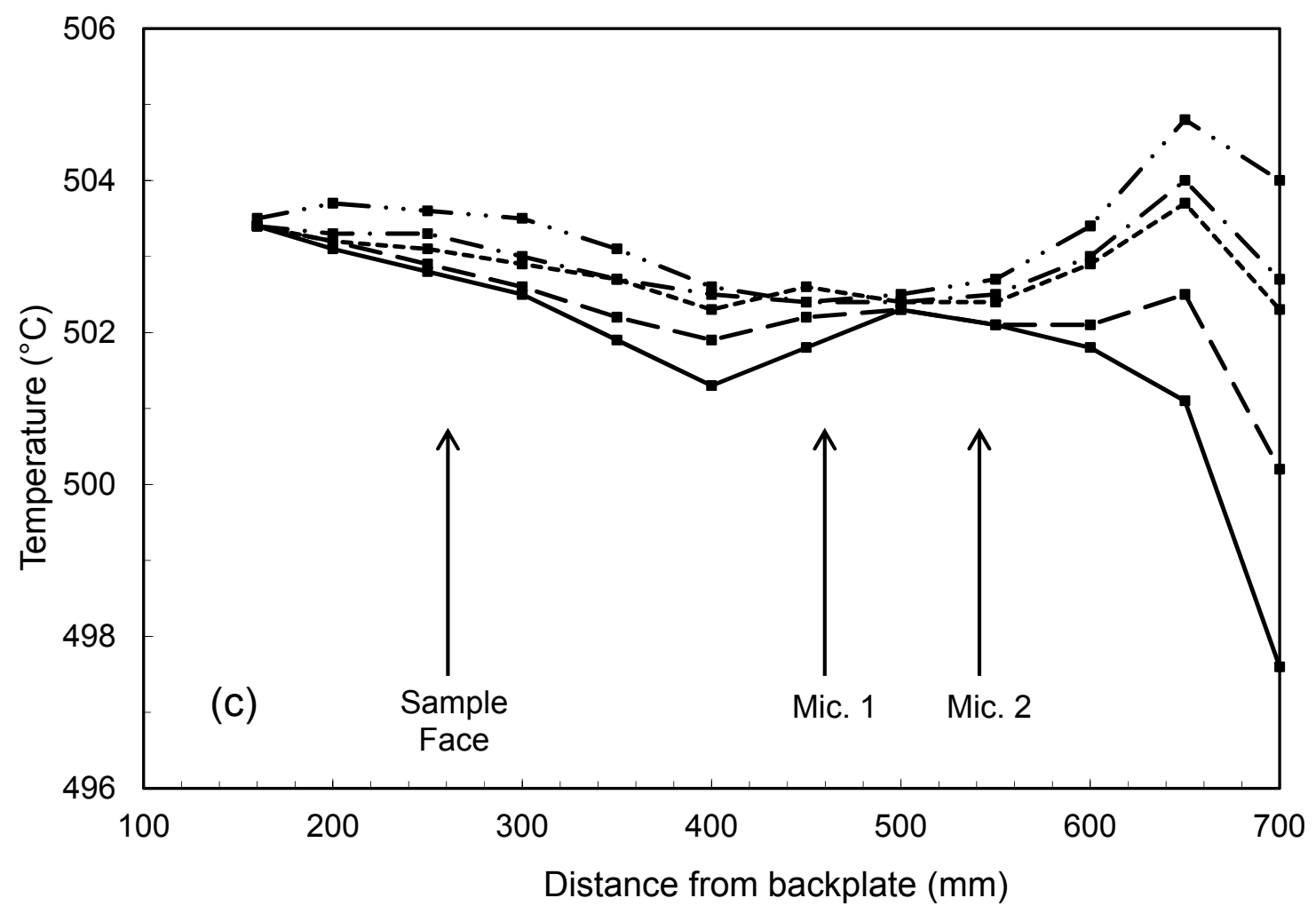

Figure 3(c). Measured temperature inside tube at set temperature of $500^{\circ} \mathrm{C}$ and a distance $y$ from the bottom of the tube. $\longrightarrow, y=10 \mathrm{~mm} ;---, y=30 \mathrm{~mm}$; ….........,$y=50 \mathrm{~mm} ;-\cdot-\cdot, y=70 \mathrm{~mm} ;-\cdots-\cdot, y=90 \mathrm{~mm}$. 


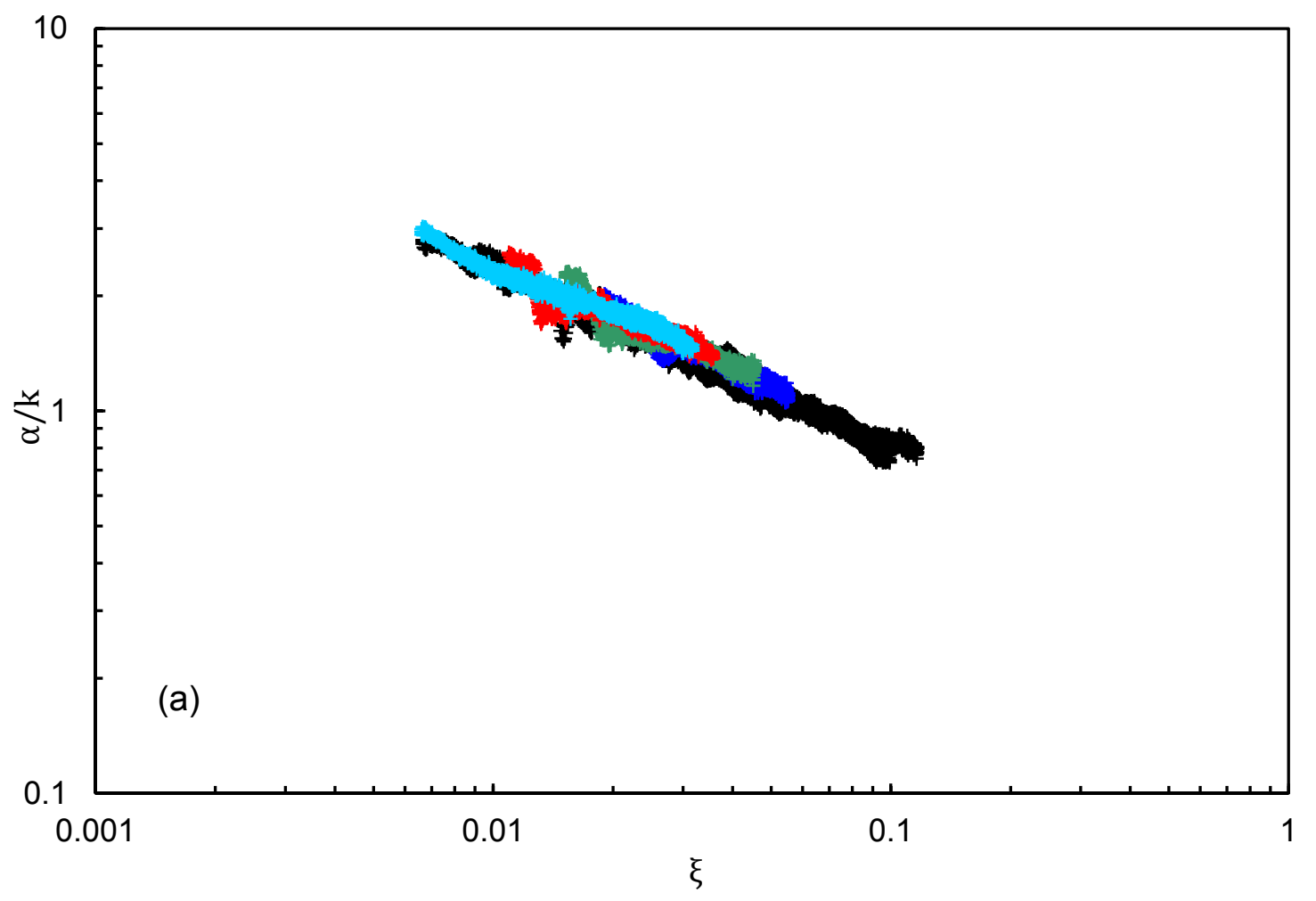

Figure 4a. Real part of the propagation constant for rock wool. $\quad+\quad, 20^{\circ} \mathrm{C}$; $+\quad, 200^{\circ} \mathrm{C} ; \quad+\quad, 300^{\circ} \mathrm{C} ; \quad+400^{\circ} \mathrm{C} ; \quad+\quad 500^{\circ} \mathrm{C}$. 


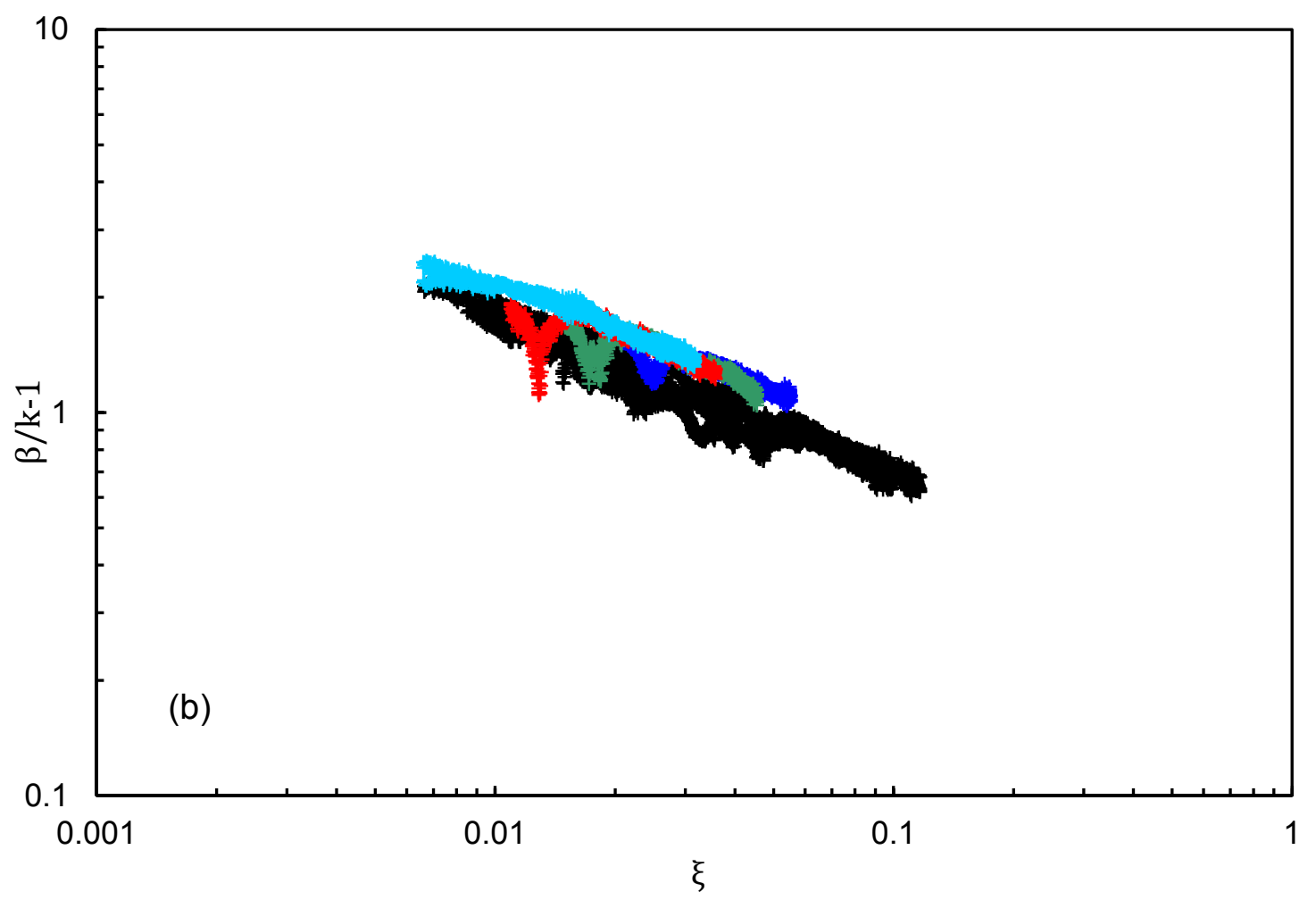

Figure 4(b). Imaginary part of the propagation constant for rock wool. $\quad+\quad, 20^{\circ} \mathrm{C}$; $+\quad, 200^{\circ} \mathrm{C} ; \quad+\quad, 300^{\circ} \mathrm{C} ; \quad+400^{\circ} \mathrm{C} ; \quad+500^{\circ} \mathrm{C}$. 


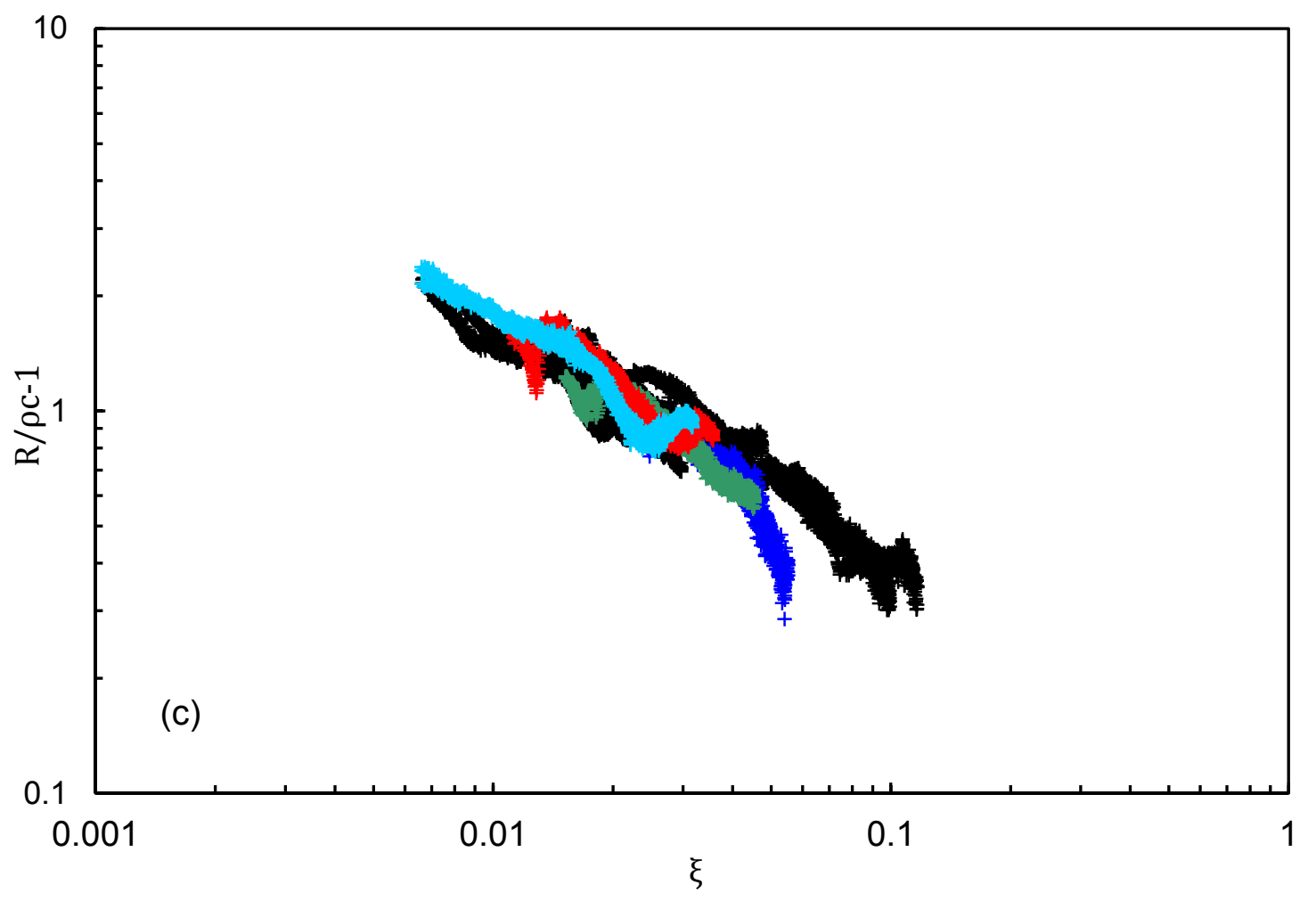

Figure 4(c). Real part of the characteristic impedance for rock wool. $\quad+\quad, 20^{\circ} \mathrm{C}$; $+\quad, 200^{\circ} \mathrm{C} ; \quad+\quad, 300^{\circ} \mathrm{C} ; \quad+400^{\circ} \mathrm{C} ; \quad+500^{\circ} \mathrm{C}$. 


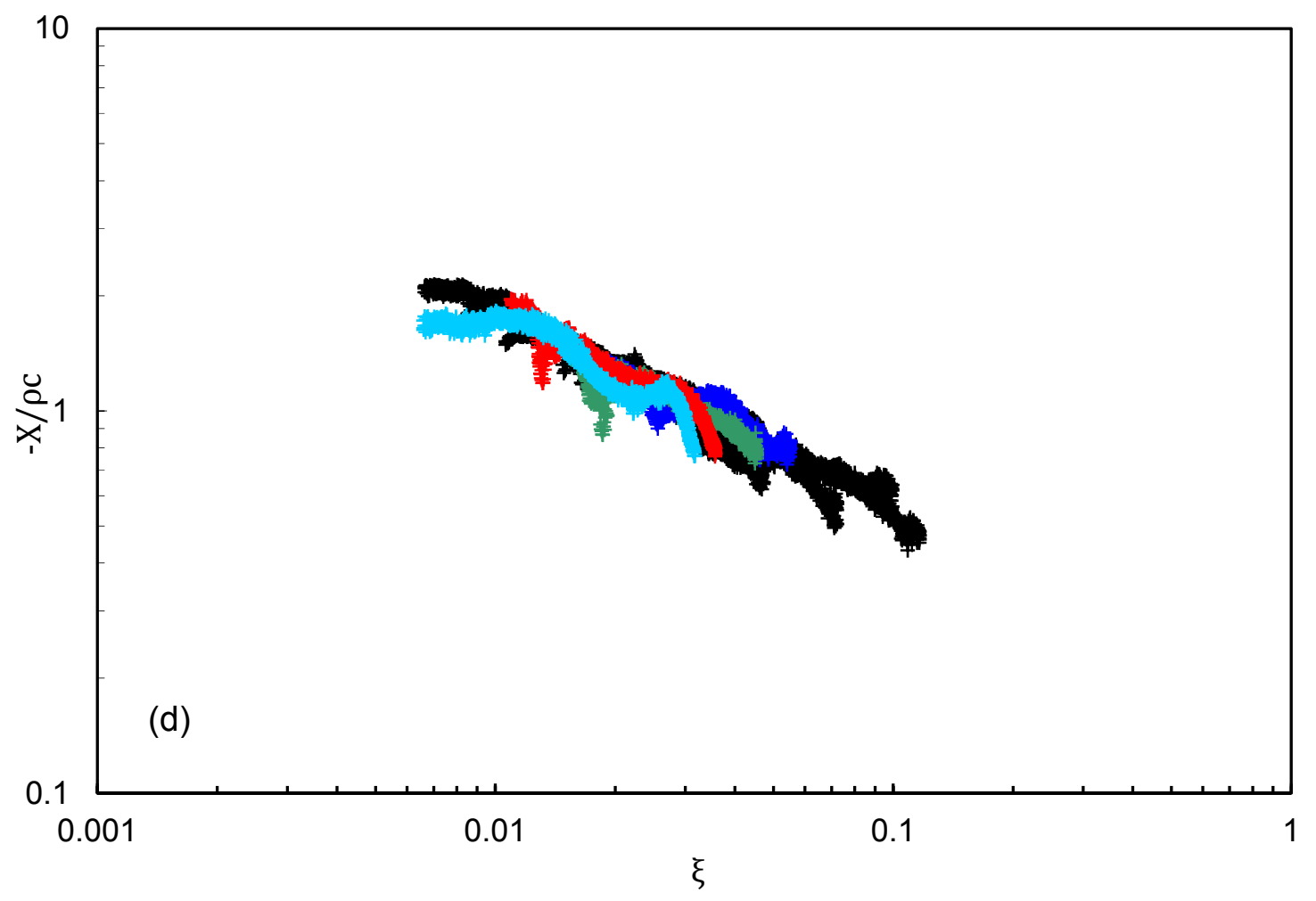

Figure 4(d). Imaginary part of the characteristic impedance for rock wool. $\quad+\quad, 20^{\circ} \mathrm{C}$; $+\quad, 200^{\circ} \mathrm{C} ; \quad+\quad, 300^{\circ} \mathrm{C} ; \quad+400^{\circ} \mathrm{C} ; \quad+500^{\circ} \mathrm{C}$. 


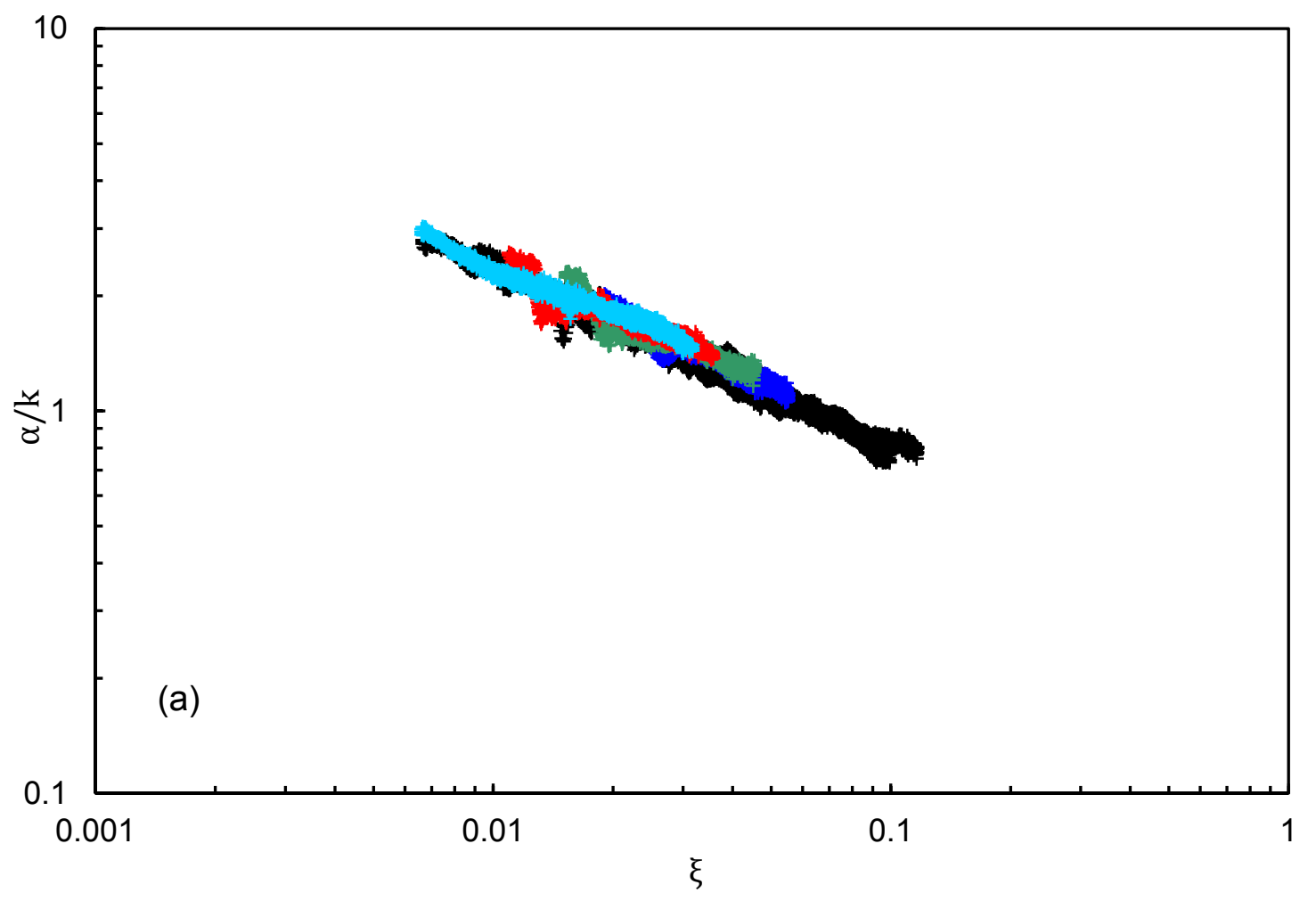

Figure 5(a). Real part of the propagation constant for basalt wool. $\quad+\quad, 20^{\circ} \mathrm{C}$; ,$+ 200^{\circ} \mathrm{C} ; \quad+, 300^{\circ} \mathrm{C} ; \quad+400^{\circ} \mathrm{C} ;+500^{\circ} \mathrm{C}$. 


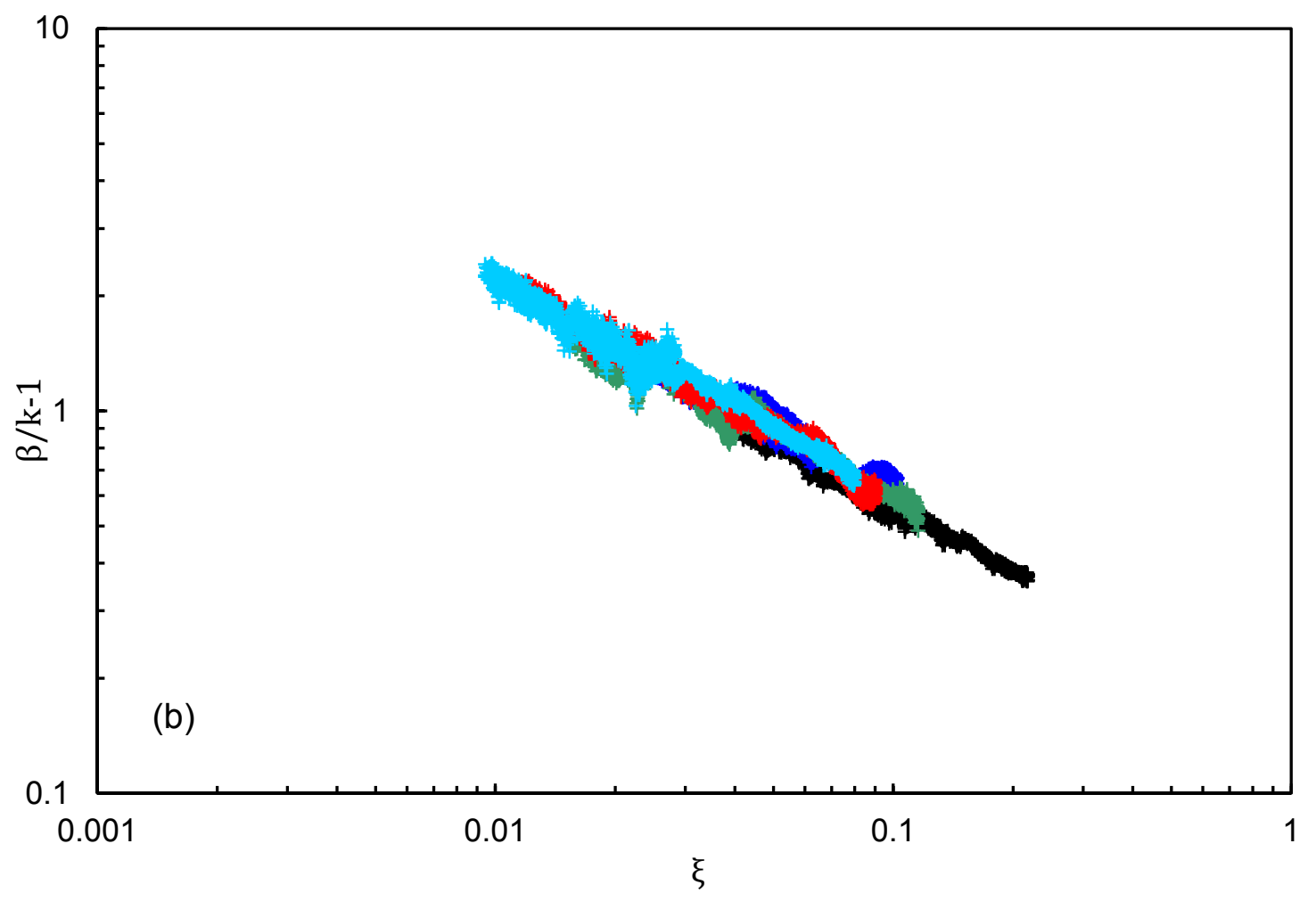

Figure 5(b). Imaginary part of the propagation constant for basalt wool. $\quad+\quad, 20^{\circ} \mathrm{C}$; $+\quad, 200^{\circ} \mathrm{C} ; \quad+\quad, 300^{\circ} \mathrm{C} ; \quad+400^{\circ} \mathrm{C} ; \quad+500^{\circ} \mathrm{C}$. 


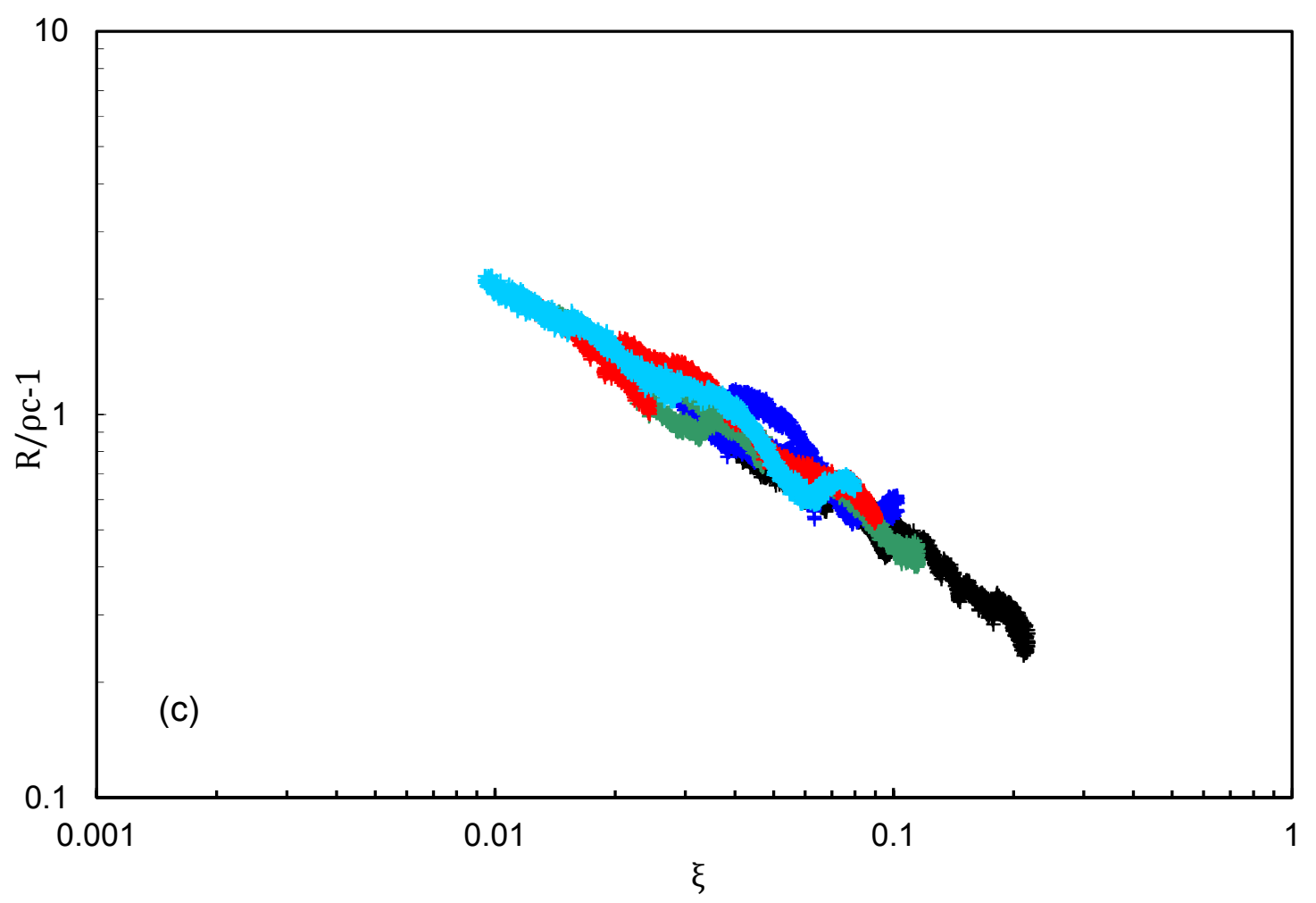

Figure 5(c). Real part of the characteristic impedance for basalt wool. $\quad+\quad, 20^{\circ} \mathrm{C}$; $+\quad, 200^{\circ} \mathrm{C} ; \quad+\quad, 300^{\circ} \mathrm{C} ; \quad+400^{\circ} \mathrm{C} ; \quad+500^{\circ} \mathrm{C}$ 


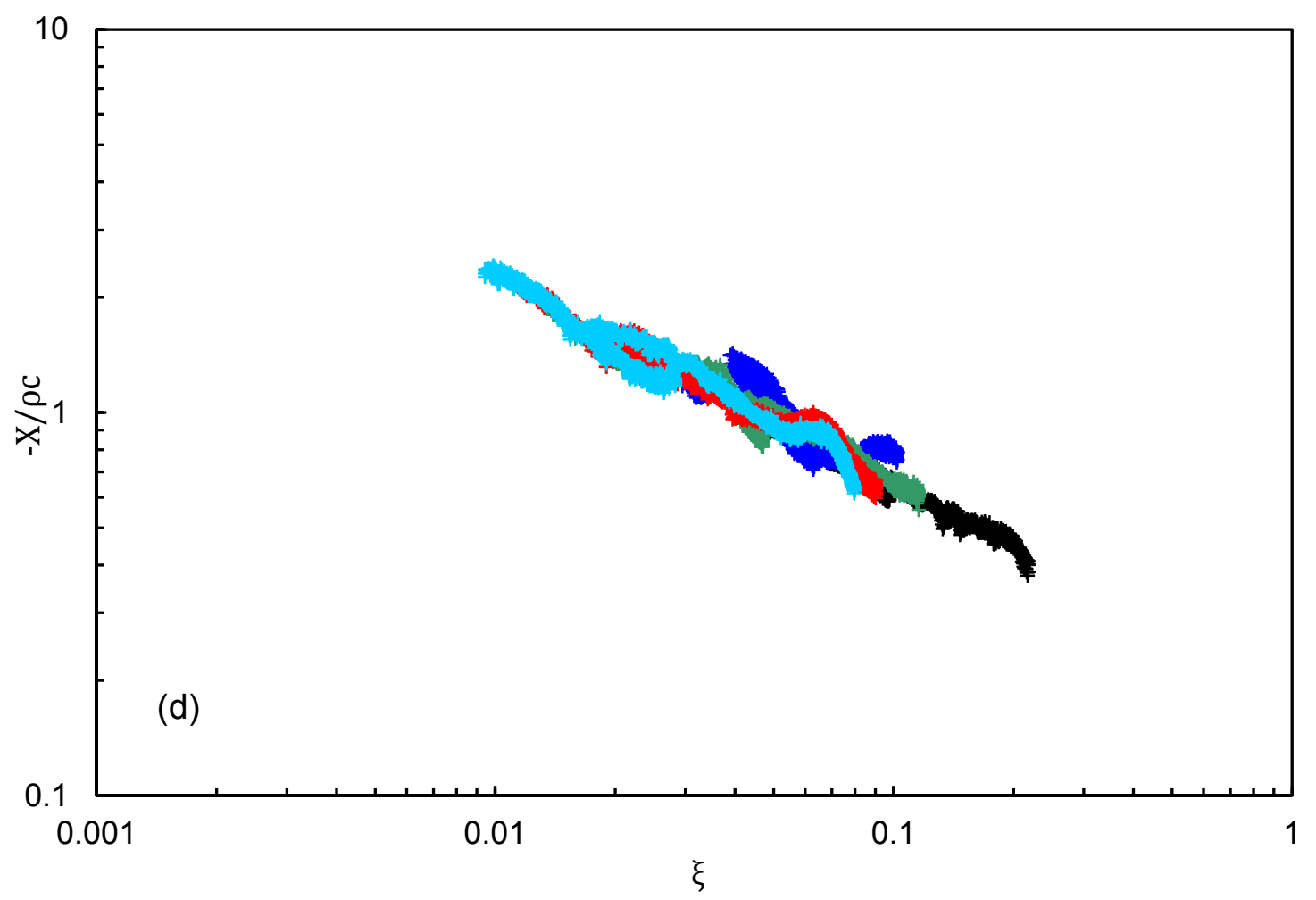

Figure 5(d). Imaginary part of the characteristic impedance for basalt wool. $\quad+\quad, 20^{\circ} \mathrm{C}$; $+\quad, 200^{\circ} \mathrm{C} ; \quad+\quad, 300^{\circ} \mathrm{C} ; \quad+400^{\circ} \mathrm{C} ; \quad+500^{\circ} \mathrm{C}$. 


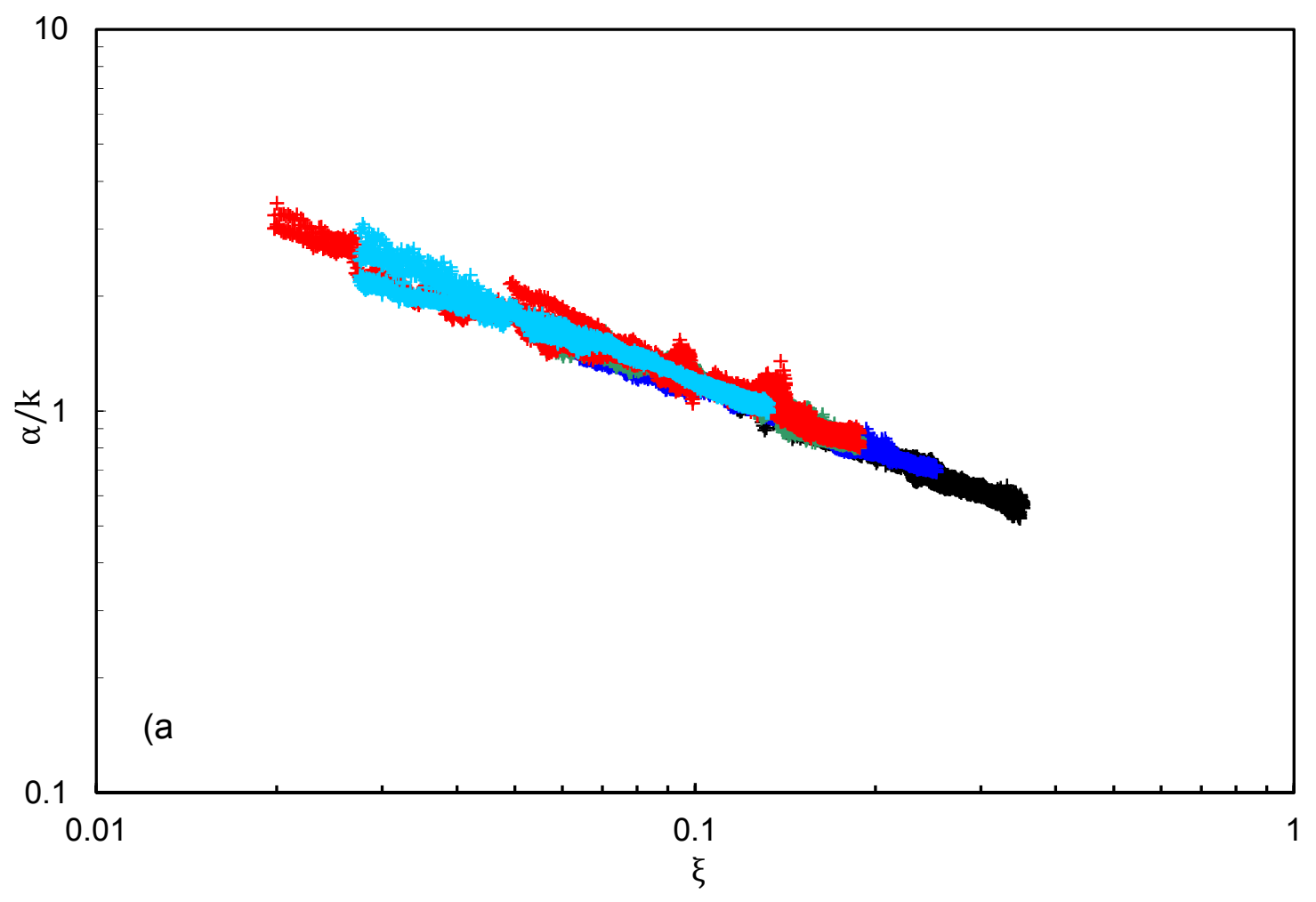

Figure 6(a). Real part of the propagation constant for glass fibre. $\quad+\quad, 20^{\circ} \mathrm{C}$; $+\quad, 200^{\circ} \mathrm{C} ; \quad+\quad, 300^{\circ} \mathrm{C} ; \quad+\quad 400^{\circ} \mathrm{C} ; \quad+\quad 500^{\circ} \mathrm{C}$. 


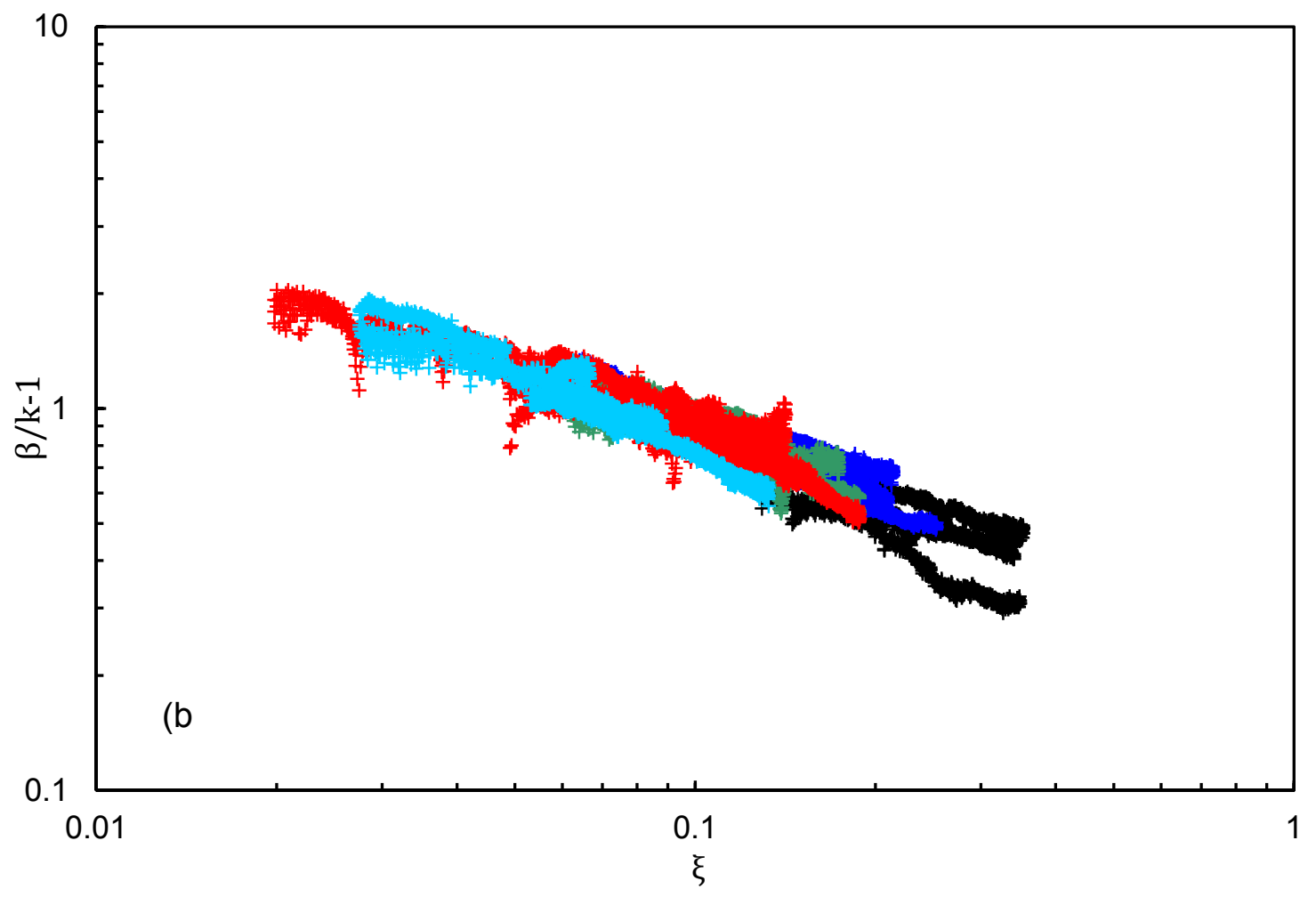

Figure 6(b). Imaginary part of the propagation constant for rock wool. $\quad+\quad, 20^{\circ} \mathrm{C}$; $+\quad, 200^{\circ} \mathrm{C} ; \quad+\quad, 300^{\circ} \mathrm{C} ; \quad+\quad 400^{\circ} \mathrm{C} ; \quad+\quad 500^{\circ} \mathrm{C}$. 


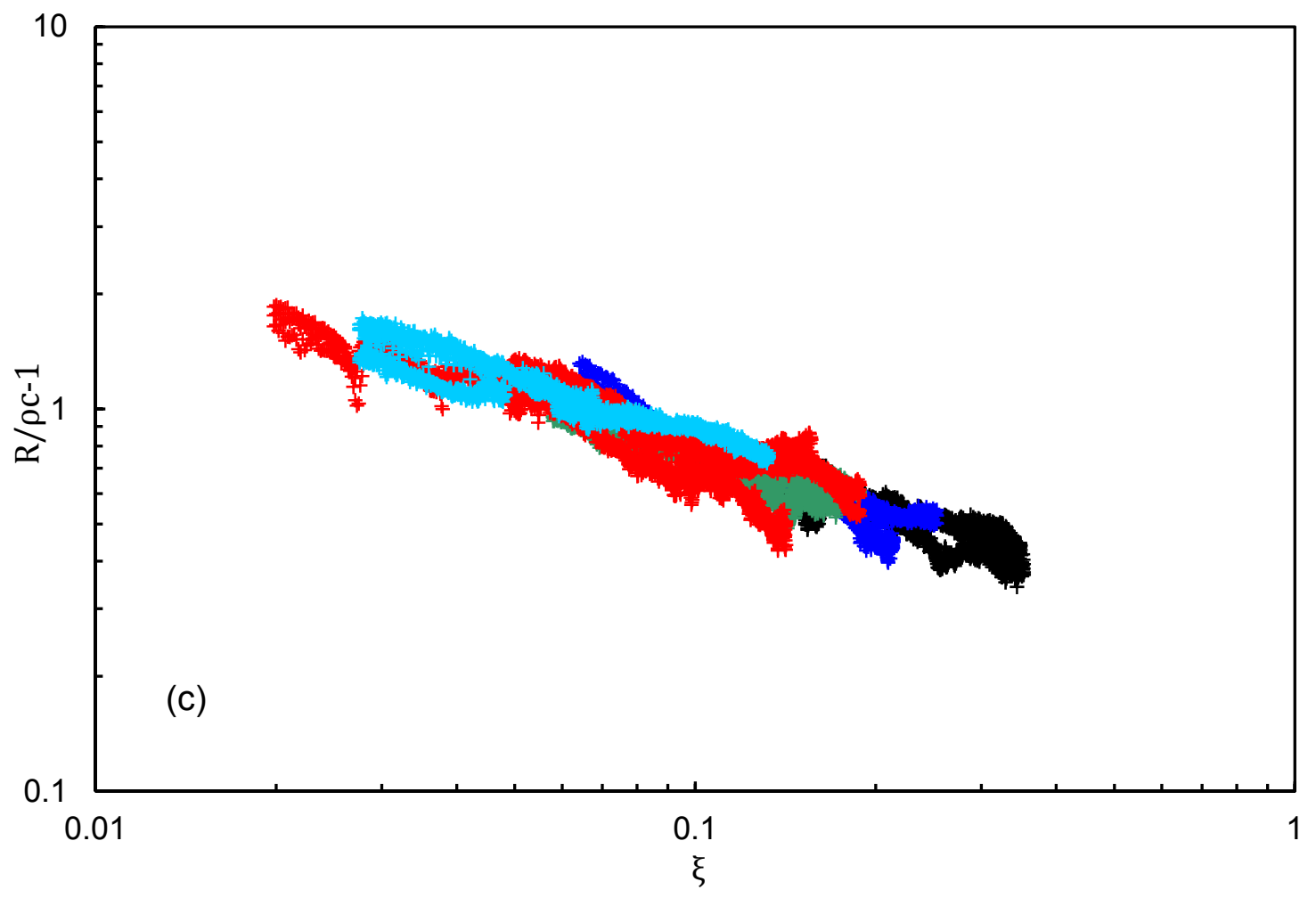

Figure 6(c). Real part of the characteristic impedance for glass fibre $\quad+\quad, 20^{\circ} \mathrm{C}$; $+\quad, 200^{\circ} \mathrm{C} ; \quad+\quad, 300^{\circ} \mathrm{C} ; \quad+\quad 400^{\circ} \mathrm{C} ; \quad+\quad 500^{\circ} \mathrm{C}$. 


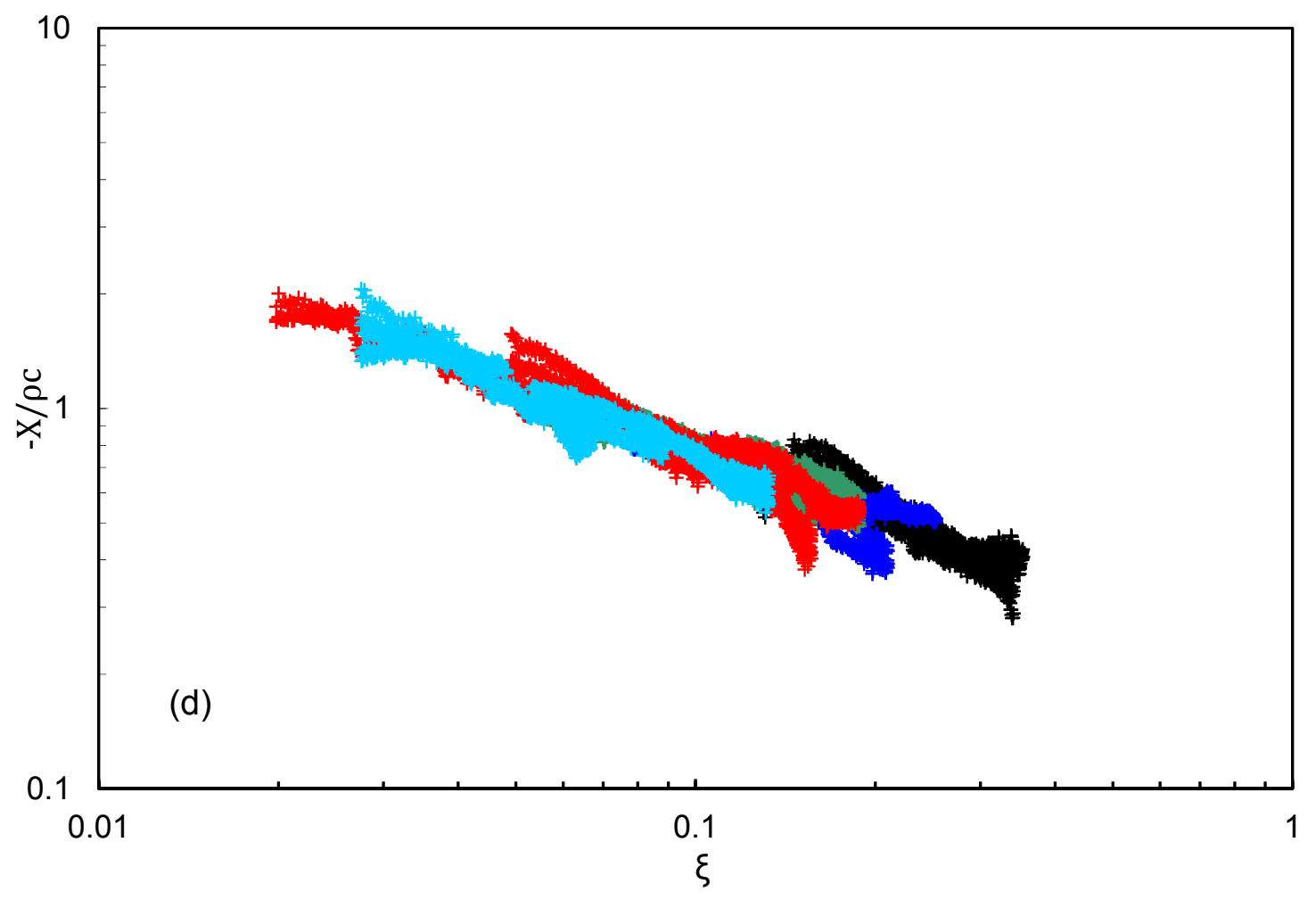

Figure 6(d). Imaginary part of the characteristic impedance for glass fibre. $\quad+\quad, 20^{\circ} \mathrm{C}$; $+\quad, 200^{\circ} \mathrm{C} ; \quad+\quad, 300^{\circ} \mathrm{C} ; \quad+\quad 400^{\circ} \mathrm{C} ; \quad+\quad 500^{\circ} \mathrm{C}$. 


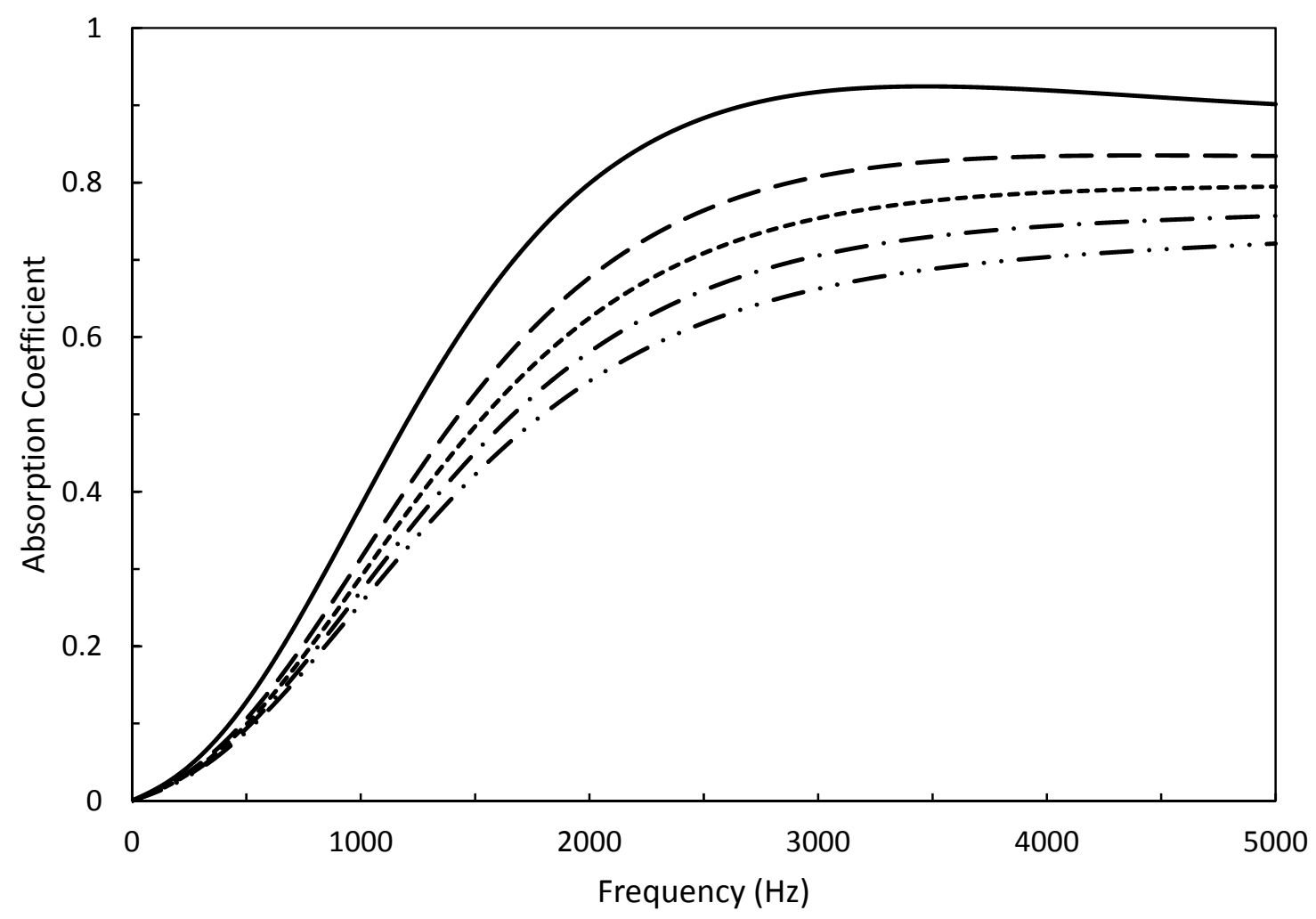

Figure 7. The absorption coefficient of basalt wool calculated from the derived Delany and Bazley coefficients.,$- 20^{\circ} \mathrm{C} ;---, 200^{\circ} \mathrm{C}$; $\cdots \cdots \cdots \cdots \cdots \cdot 300^{\circ} \mathrm{C} ;-\cdot-\cdot-, 400^{\circ} \mathrm{C} ;-\cdots-\cdot, 500^{\circ} \mathrm{C}$. 
Table 1. Measured regression coefficients

\begin{tabular}{cccc}
\hline & Rock Wool & Basalt Wool & Glass Fibre \\
\hline$a_{1}$ & 0.272 & 0.242 & 0.330 \\
$a_{2}$ & -0.472 & -0.568 & -0.557 \\
$a_{3}$ & 0.243 & 0.164 & 0.255 \\
$a_{4}$ & -0.433 & -0.561 & -0.539 \\
$a_{5}$ & 0.132 & 0.116 & 0.241 \\
$a_{6}$ & -0.540 & -0.641 & -0.507 \\
$a_{7}$ & 0.159 & 0.203 & 0.211 \\
$a_{8}$ & -0.533 & -0.515 & -0.563 \\
$b_{1}$ & 0.164 & 1.939 & 0.616 \\
$b_{2}$ & 2.748 & 1.850 & 1.946
\end{tabular}

